OPEN ACCESS

Edited by:

Alexander N. Shikov,

Saint-Petersburg State Chemical

Pharmaceutical Academy, Russia

Reviewed by:

Olga Pozharitskaya,

Murmansk Marine Biological Institute,

Russia

Nikolay Polyakov,

Institute of Chemical Kinetics and

Combustion (RAS), Russia

${ }^{*}$ Correspondence:

Jun-zhi Lin

582097013@qq.com

Ding-kun Zhang

zhangdingkun@cdutcm.edu.cn

Li Han

hanliyx@163.com

${ }^{t}$ These authors have contributed equally to this work

Specialty section:

This article was submitted to

Ethnopharmacology,

a section of the journal

Frontiers in Pharmacology

Received: 03 June 2021

Accepted: 29 October 2021

Published: 26 November 2021

Citation:

Zhang Q-h, Huang H-z, Qiu M, Wu Z-f,

Xin Z-c, Cai X-f, Shang Q, Lin J-Z,

Zhang D-k and Han L (2021)

Traditional Uses, Pharmacological

Effects, and Molecular Mechanisms of Licorice in Potential Therapy of COVID-

Front. Pharmacol. 12:719758. doi: $10.3389 /$ fphar.2021.719758

\title{
Traditional Uses, Pharmacological Effects, and Molecular Mechanisms of Licorice in Potential Therapy of COVID-19
}

Qian-hui Zhang ${ }^{1 \dagger}$, Hao-zhou Huang ${ }^{1 \dagger}$, Min Qiu ${ }^{1}$, Zhen-feng Wu ${ }^{2}$, Zhan-chang Xin ${ }^{3}$,
Xin-fu Cai ${ }^{4,5}$, Qiang Shang ${ }^{4,5}$, Jun-zhi Lin ${ }^{6 *}$, Ding-kun Zhang ${ }^{1 *}$ and Li Han ${ }^{1 *}$

${ }^{1}$ State Key Laboratory of Southwestern Chinese Medicine Resources, Pharmacy School, Chengdu University of Traditional Chinese Medicine, Chengdu, China, ${ }^{2}$ Jiangxi University of Traditional Chinese Medicine, Nanchang, China, ${ }^{3}$ Gansu Qilian Mountain Pharmaceutical Limited Liability Company, Jiuquan, China, ${ }^{4}$ Sichuan Guangda Pharmaceutical Co. Ltd, Pengzhou, China, ${ }^{5}$ National Engineering Research Center for Modernization of Traditional Chinese Medicine, Pengzhou, China, ${ }^{6}$ TCM Regulating Metabolic Diseases Key Laboratory of Sichuan Province, Hospital of Chengdu University of Traditional Chinese Medicine, Chengdu, China

The current Coronavirus disease 2019 (COVID-19) pandemic has become a global challenge, and although vaccines have been developed, it is expected that mild to moderate patients will control their symptoms, especially in developing countries. Licorice, not only a food additive, but also a common traditional Chinese herbal medicine, which has several pharmacological effects, such as anti-inflammation, detoxification, antibacterial, antitussive, and immunomodulatory effects, especially in respiratory diseases. Since the outbreak of COVID-19, glycyrrhizin, glycyrrhizin diamine and glycyrrhizin extract have been widely studied and used in COVID-19 clinical trials. Therefore, it is a very interesting topic to explore the material basis, pharmacological characteristics and molecular mechanism of licorice in adjuvant treatment of COVID-19. In this paper, the material basis of licorice for the prevention and treatment of COVID-19 is deeply analyzed, and there are significant differences among different components in different pharmacological mechanisms. Glycyrrhizin and glycyrrhetinic acid inhibit the synthesis of inflammatory factors and inflammatory mediators by blocking the binding of ACE 2 to virus spike protein, and exert antiviral and antibacterial effects. Immune cells are stimulated by multiple targets and pathways to interfere with the pathogenesis of COVID-19. Liquiritin can prevent and cure COVID-19 by simulating type I interferon. It is suggested that licorice can exert its therapeutic advantage through multi-components and multi-targets. To sum up, licorice has the potential to adjuvant prevent and treat COVID-19. It not only plays a significant role in anti-inflammation and anti-ACE-2, but also significantly improves the clinical symptoms of fever, dry cough and shortness of breath, suggesting that licorice is expected to be a candidate drug for adjuvant treatment of patients with early / mild COVID-19.

Keywords: COVID-19, licorice, traditional uses, pharmacological effects, mechanism of action 


\section{INTRODUCTION}

Since the outbreak of COVID-19 (December 12, 2019), there has been more than 240.34 million confirmed cases, and the epidemic situation is still grim all over the world. In view of the fact that it will take time for COVID-19 vaccine to be widely vaccinated all over the world, especially the great threat posed by virus mutation to people in developing countries, there is an urgent need to find safe complementary and alternative treatments to make up for the gap in vaccination temporarily. In addressing the COVID-19 epidemic around the world, the integration of traditional Chinese and Western medicine has become a significant feature of the "China plan." Traditional Chinese medicine has been used in the prevention and treatment of epidemic diseases for thousands of years, from smallpox and ancient plagues to avian influenza, middle east respiratory syndrome (MERS), severe acute respiratory syndrome (SARS), and so on (Lin et al., 2017). According to Stanford University scholars and researchers at the University of Hong Kong, severe acute respiratory syndrome coronavirus 2 (SARS-CoV2) enters the cells through the same path as the SARS coronavirus, that is to say, by the angiotensinconverting enzyme 2 (ACE2) cell receptor, which proves that glycyrrhizin can bind to part of the binding site of ACE2, indicating that glycyrrhizin has potential application for inhibiting SARS-CoV2 (Zhou P. et al., 2020). Meanwhile, the other study has mentioned that glycyrrhizin could significantly prevent the binding of novel coronavirus spikes protein to the human target protein ACE2, confirming that glycyrrhizin is an effective bioactive components against COVID-19 (Yu et al., 2020). Additionally, according to a team at Peking University, liquiritin can inhibit COVID-19 by simulating type I interferon (ZhuJie et al., 2020). Therefore, it certainly has a reference point for exploring the mechanism and bioactive components of licorice in the treatment of COVID-19.

Licorice, the dried root and rhizome of the plant Glycyrrhiza uralensis Fisch. ex DC., Glycorrhiza inflata Bat., Glycyrrhiza glabra L.. It has various effects, including clearing heat and removing the toxin, relieving pain and cough, dispelling phlegm, and reconciling numerous medicines (Wang et al., 2019). Licorice has a long history of medicinal use in both Eastern and Western civilizations. In the West, Romans, Greeks, the scriptures of Ayurveda, and the ancient Egyptians mentioned the beneficial effects of licorice in traditional treatment of colds, coughs, and chills. For example, In IV-III century B.C., the Greeks first used licorice as a medicine in Europe to treat asthma, lung disease, and cough. In IV-V century A.D., licorice was used to relieve fever, influenza syndrome, nourish blood, and restore blood circulation (Wang J. et al., 2013). The Romans recommended licorice to treat lung diseases. Since the VIII-IX century A.D., licorice was used to relieve cough to treat various lung diseases (Fiore et al., 2005). Since the Middle Ages, Germans have used licorice to relieve diseases such as arterial disease, palpitations, and angina pectoris. In the East, it has a history of more than 2,000 years of medicinal use. It has been widely used to treat various diseases, such as respiratory diseases, fever, hypertension, gastric ulcers, paralysis, rheumatism, sexual weakness, and hemorrhagic diseases.
According to the theory of traditional Chinese medicine, licorice has a unique conditioning effect on respiratory diseases, viral cough, viral hepatitis, and other diseases. Although licorice has many pharmacological effects, and often be used as a unique "guiding medicine" in more than half of the traditional and modern prescriptions and prescriptions. The regulatory effects of licorice on other herbs include significant detoxification, treatment of drug and food poisoning, or inhibition of adverse reactions, and this "guiding" effect has been tested in many formulations. In India, licorice is widely used to treat influenza, eye disease, gallstones, liver disease and arthritis (Zhang et al., 2020). In Japan, licorice is widely used to detoxify, relieve cough, and relieve pain. In the 1940s, Japanese pharmaceutical company Minuofa (Minophagen) Pharmaceutical Co., Ltd. successfully extracted glycyrrhizin from licorice and formed a compound preparation Stronger Neo-Minophagen $\mathrm{C}$ with glycine and cysteine, which has been used as anti-allergy and anti-hepatitis drugs in the clinic. Additionally, because licorice, as a monoamine oxidase inhibitor, has anticholinergic, antitussive, hypolipidemic, antifungal, antioxidant, and anticancer effects, it has traditionally been used as anti-inflammatory, anti-ulcer, antibiotic, anti-arthritic, antiviral, laxative, memory stimulant (Zadeh et al., 2013). Since the 18th century, licorice has been used in various food, industrial, pharmaceutical, and cosmetic applications, with sound therapeutic effects and high safety. Meanwhile, licorice is added to many foods as an important spice. In modern food production, licorice is widely used in beverages, beer, meat and other foods as sweeteners, antioxidants, antimicrobials, foaming agents and flavor enhancers. It is a recognized food additive in the Europe, the United States and China (Montoro et al., 2011; Di Lorenzo et al., 2015; Li et al., 2016; Xu et al., 2016; Alam et al., 2017; Indhu and Shajahan, 2018). Modern pharmacological studies have shown that licorice has numerous effects, such as anti-inflammatory, antiviral, antibacterial, and immunomodulatory, as well as certain hypoglycemic, anti-obesity, and detoxification effects (Yang et al., 2015; Luo et al., 2020). Licorice is used in Russian traditional and officinal medicine as an expectorant and emollient, which is related to anti-inflammatory properties. However, all medicines of licorice are available in Russia in Pharmacies as OTC products in European Union (Shikov Alexander et al., 2021). Among them, the present study showed that licorice could cure infection related ailments with the establishment of glabridin as a potent lead molecule for activity (Fatima et al., 2009).

Bailly et al. proposed that glycyrrhizin has a potential use in the treatment of coronavirus infection, but this article focuses on the description of the mechanism of anti-virus (mainly anti-HIV effect, anti-animal virus effect) and antiinflammatory activity (mainly skin inflammation) of glycyrrhizin, and does not comprehensively review the related mechanism of licorice in the prevention and treatment of all potential active components of COVID-19 (Bailly and Vergoten, 2020). According to existing research findings, the pharmacological effects of licorice and natural products like glycyrrhizin, liquiritin and other active 
TABLE 1 | The potential components of licorice.

\begin{tabular}{|c|c|c|c|c|}
\hline Number & Component & $\begin{array}{l}\text { Molecular } \\
\text { formula }\end{array}$ & Pharmacological activity & References \\
\hline 1 & Glycyrrhizin & $\mathrm{C}_{42} \mathrm{H}_{62} \mathrm{O}_{16}$ & $\begin{array}{l}\text { Anti-inflammatory, antiviral, antibacterial, immunomodulatory, anti-pulmonary } \\
\text { fibrosis, and inhibition of ACE2 }\end{array}$ & $\begin{array}{l}\text { Altay et al. (2016); El-Saber Batiha } \\
\text { et al. (2020) }\end{array}$ \\
\hline 2 & Liquiritin & $\mathrm{C}_{21} \mathrm{H}_{22} \mathrm{O}_{9}$ & Antiviral, immunomodulatory & El-Saber Batiha et al. (2020) \\
\hline 3 & Isoliquiritin & $\mathrm{C}_{21} \mathrm{H}_{22} \mathrm{O}_{9}$ & Anti-inflammatory, immunomodulatory & El-Saber Batiha et al. (2020) \\
\hline 4 & Liquiritigenin & $\mathrm{C}_{15} \mathrm{H}_{12} \mathrm{O}_{4}$ & Anti-inflammatory, antiviral, antibacterial, immunomodulatory & $\begin{array}{l}\text { Öztürk et al. (2018); El-Saber Batiha } \\
\text { et al. (2020) }\end{array}$ \\
\hline 5 & Isoliquiritigenin & $\mathrm{C}_{15} \mathrm{H}_{12} \mathrm{O}_{4}$ & Anti-inflammatory, antiviral, antibacterial & Yang et al. (2017) \\
\hline 6 & Neoisoliquiritin & $\mathrm{C}_{21} \mathrm{H}_{22} \mathrm{O}_{9}$ & Anti-inflammatory & El-Saber Batiha et al. (2020) \\
\hline 7 & Licoflavonol & $\mathrm{C}_{20} \mathrm{H}_{18} \mathrm{O}_{6}$ & Anti-inflammatory & El-Saber Batiha et al. (2020) \\
\hline 8 & Isolicoflavonol & $\mathrm{C}_{20} \mathrm{H}_{18} \mathrm{O}_{6}$ & Anti-inflammatory & El-Saber Batiha et al. (2020) \\
\hline 9 & Licochalcone A & $\mathrm{C}_{21} \mathrm{H}_{22} \mathrm{O}_{4}$ & Anti-inflammatory, antiviral, antibacterial, immunomodulatory & Yang et al. (2017) \\
\hline 10 & Licochalcone B & $\mathrm{C}_{16} \mathrm{H}_{14} \mathrm{O}_{5}$ & Anti-inflammatory, antiviral, immunomodulatory & Yang et al. (2017) \\
\hline 11 & Licochalcone C & $\mathrm{C}_{21} \mathrm{H}_{22} \mathrm{O}_{4}$ & Anti-inflammatory, antiviral, immunomodulatory & Yang et al. (2017) \\
\hline 12 & Licochalcone D & $\mathrm{C}_{21} \mathrm{H}_{22} \mathrm{O}_{5}$ & Anti-inflammatory, antiviral, immunomodulatory & Yang et al. (2017) \\
\hline 13 & Licoricone & $\mathrm{C}_{22} \mathrm{H}_{22} \mathrm{O}_{6}$ & Anti-inflammatory & El-Saber Batiha et al. (2020) \\
\hline 14 & Glabridin & $\mathrm{C}_{20} \mathrm{H}_{20} \mathrm{O}_{4}$ & Anti-inflammatory, antibacterial, vascular protection & Yang et al. (2017) \\
\hline 15 & Glabrene & $\mathrm{C}_{20} \mathrm{H}_{20} \mathrm{O}_{4}$ & Anti-inflammatory & El-Saber Batiha et al. (2020) \\
\hline 16 & Glabranin & $\mathrm{C}_{20} \mathrm{H}_{20} \mathrm{O}_{4}$ & Anti-inflammatory & El-Saber Batiha et al. (2020) \\
\hline 17 & Uralenin & $\mathrm{C}_{20} \mathrm{H}_{18} \mathrm{O}_{6}$ & Anti-inflammatory & El-Saber Batiha et al. (2020) \\
\hline 18 & $\begin{array}{l}\text { Licocoumarin } \\
\text { A }\end{array}$ & $\mathrm{C}_{25} \mathrm{H}_{26} \mathrm{O}_{5}$ & Anti-inflammatory & El-Saber Batiha et al. (2020) \\
\hline 19 & Kanzonol R & $\mathrm{C}_{22} \mathrm{H}_{26} \mathrm{O}_{5}$ & Antiviral & El-Saber Batiha et al. (2020) \\
\hline
\end{tabular}

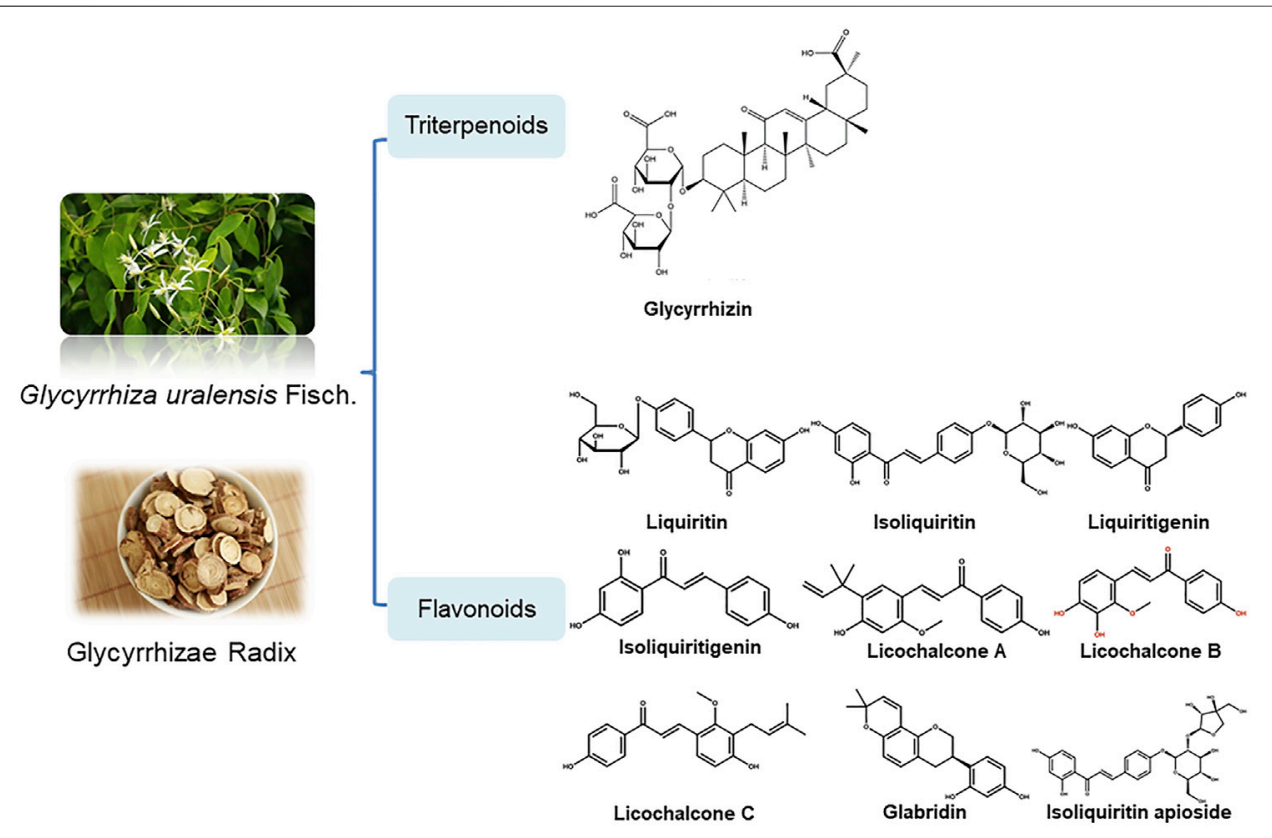

FIGURE 1 | Structural formula of potential components of licorice.

components have beneficial effects to prevent some immunological responses triggered by COVID-19. The potential mechanism could be that they play an overall regulatory role through multi-components and multi-targets to participate in biological processes (Altay et al., 2016; Yang et al., 2017; Öztürk et al., 2018; EI-Saber et al., 2020) (Table 1; Figure 1.). Therefore, the object of this review will be expanded to licorice for the prevention and treatment of all potential active components of COVID-19, to comprehensively explore the pharmacological effects and 


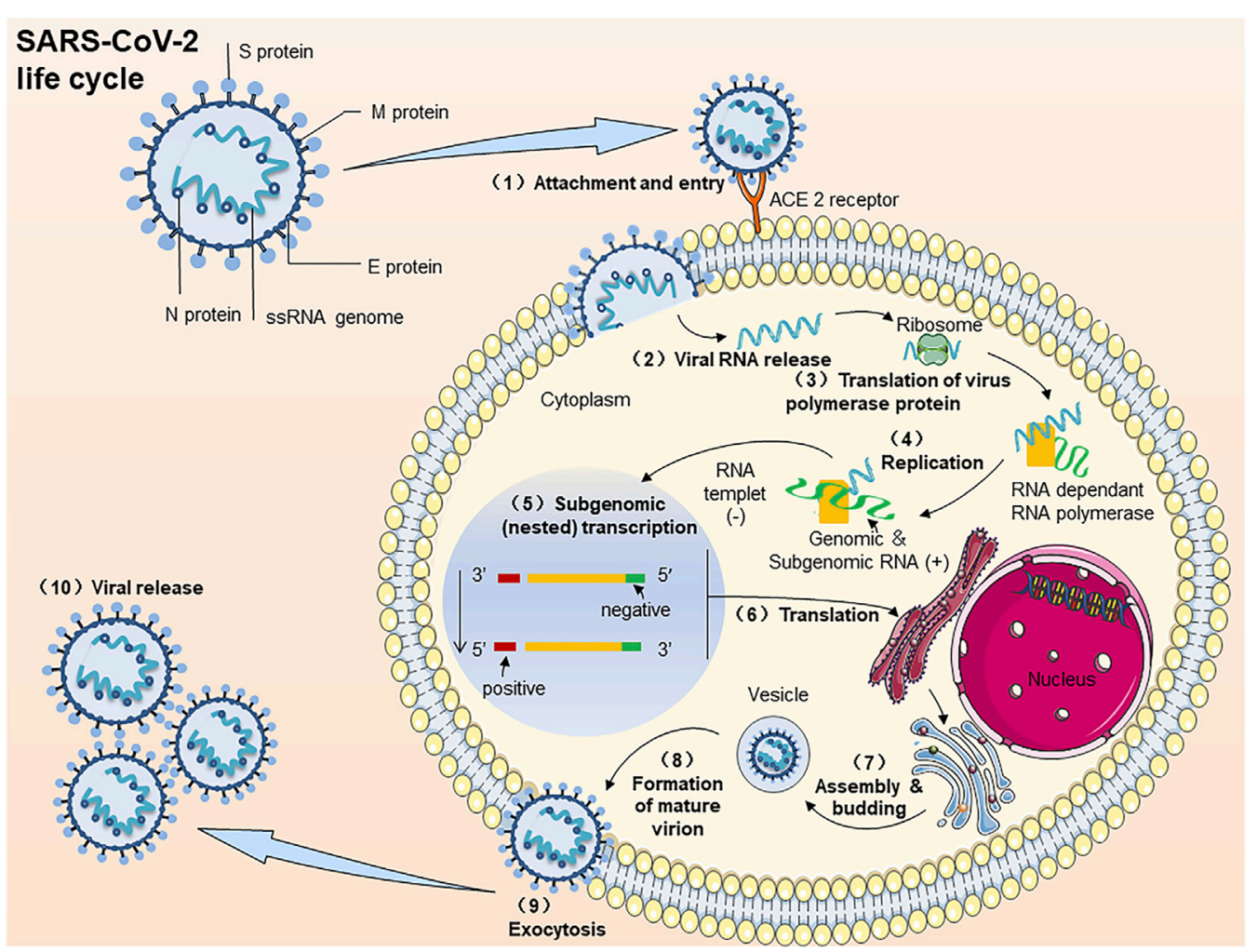

FIGURE 2| The process of SARS-CoV2 virus infection of host cells. Note: The replication cycle of SARS-CoV2 in virus-susceptible host cells: (1) ACE2 binds to the RBD of the spike protein (S) and then fuses with the host cell membrane. (2) Release the positive single-stranded RNA. (3, 4) Partially translate into SARS-CoV2 polymerase protein. (5) Transcribe. (6) The resulting subgenomic RNA translated S, M, and E proteins are transported to the ER membrane of the host cell and then bind to the nucleocapsid protein (N). (7) To-after processing in the Golgi apparatus. (8) Mature virus particles are formed and transported to the cell membrane. (10) New SARS-CoV2 particles are excreted by exocytosis (9).

mechanism of action of licorice in potential treatment and discusses the practicability of its clinical treatments for COVID-19.

\section{PATHOGENESIS OF COVID-19}

COVID-19 is triggered by SARS-CoV2. Similar to SARS and MERS, SARS-CoV2 also belongs to $\beta$-coronavirus genus. New coronary pneumonia is caused by SARS-CoV2. It is a positive single-stranded, polymorphic enveloped RNA virus. The genome length is approximately $30 \mathrm{~kb}$, and the particle size is approximately $100-160 \mathrm{~nm}$ (Shah et al., 2020). The replication cycle of SARS-CoV2 infected host cells can be divided into several key steps (Figure 2.) (Poduri et al., 2020; Ma et al., 2021): (A) Binding; (B) Membrane fusion; (C) Translation/replication; (D) Assembly and release. Specific steps include 1) The RBD of the spike protein (S) Binds to ACE2 and then fuses with the host cell membrane. 2) release the positive single-stranded RNA. (3-4) Partially translate into SARS-CoV2 polymerase protein. 5) Transcribe 6) This resulting subgenomic RNA-translated S, M, and $\mathrm{E}$ proteins are transported to the ER membrane of the host cell and then bind to the nucleocapsid protein (N). 7) After processing in the Golgi apparatus. 8) Mature virus particles are formed and transported to the cell membrane. (10) New SARSCoV2 particles are excreted by exocytosis (9).

Since the emergence of SARS-CoV2, researchers have conducted in-depth studies on its genome sequence $1-3,8$, and viral protein structure 9-11. So far, studies have shown that SARS-CoV2 and SARS-CoV have many biological characteristics in common: there are $79.6 \%$ genomic sequence homology 1 and 2. In particular, both SARS-CoV2 and SARS$\mathrm{CoV}$ enter the system by binding viral S protein to ACE 2 on the surface of host cells. Like SARS, MERS, and SARS-CoV2 can cause respiratory infections, leading to viral pneumonia and acute respiratory distress syndrome (ARDS). Fever, cough and fatigue are the most common clinical symptoms in patients with COVID-19. Among them, the increase of C-reactive protein (CRP), the decrease of lymphocyte count, and the rise of lactate dehydrogenase are the most common clinical abnormal values. Ground glass opacity and bilateral pneumonia are the most frequently reported findings in CT (Fu et al., 2020). A large number of experimental data showed that the plasma numbers of IL-2, IL-7, IL-10, granulocyte colony-stimulating factor, interferon- $\gamma$ inducible protein, monocyte chemoattractant protein-1, macrophage inflammatory protein $1-\alpha$, and TNF- $\alpha$ were higher in patients with ICU (Guo et al., 2020). Nevertheless, besides respiratory symptoms, COVID-19 also produce a 


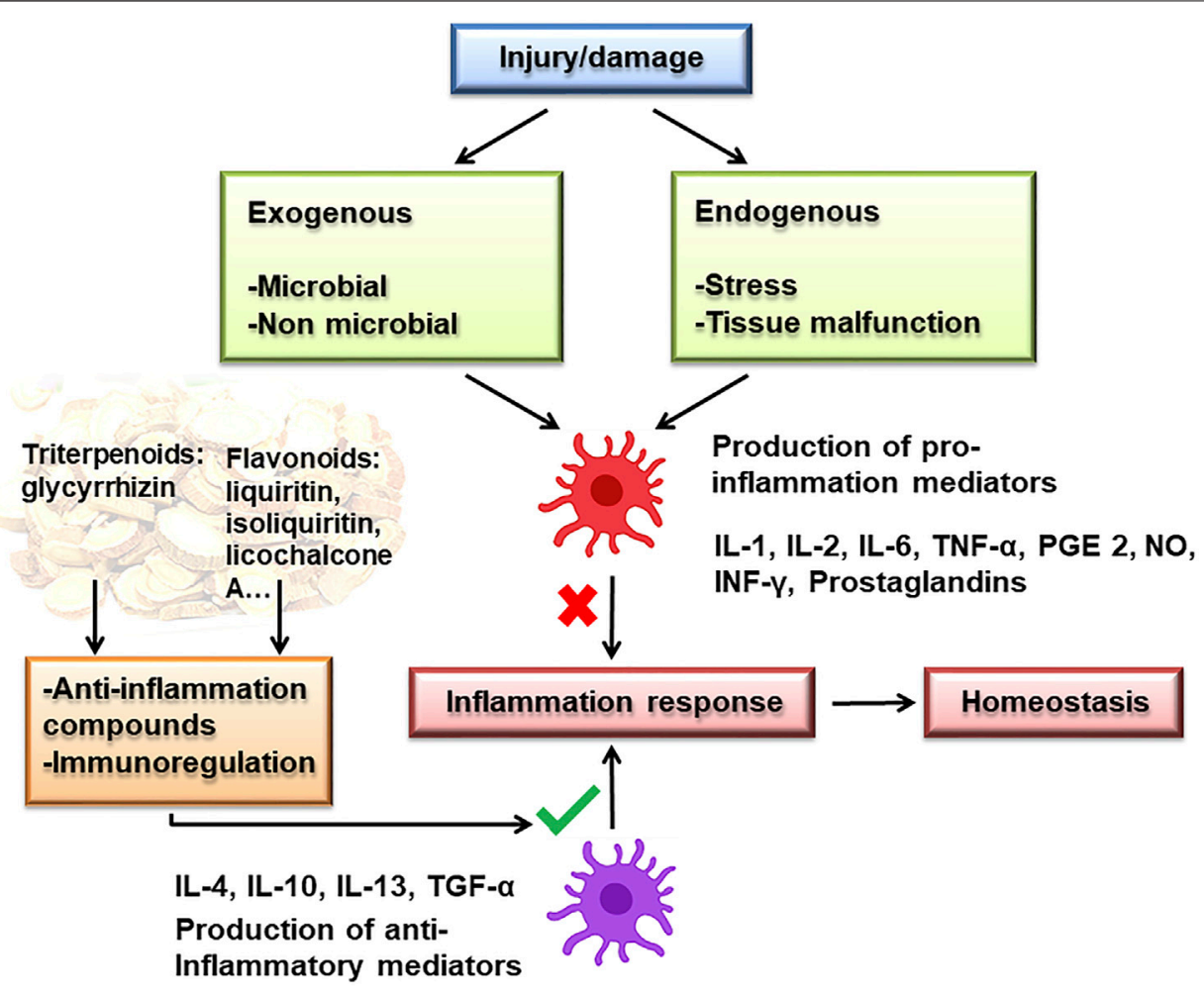

FIGURE 3 | Anti-inflammatory mechanism of licorice.

cytokine storm that causes the immune system to overproduce pro-inflammatory and chemokines, next causing abnormal blood coagulation in patients and thromboembolism, which results in multiple organ damage.

\section{EXPERIMENTAL STUDIES ON POTENTIAL TREATMENT OF COVID-19 WITH LICORICE}

\section{Anti-inflammatory Effects}

The cytokine storm not only recruits more immune cells but also the homeostasis of the immune system and the function of normal cells will also be damaged, resulting in impaired ventilation function of the lungs. Inflammation is involved in many steps in COVID-19 infection, including the increase of CRP in the early stage, increase in inflammatory factors during the treatment, and sepsis in the later stage (Mehta et al., 2020). Studies have shown that licorice and its flavonoids have antiinflammatory effects, mechanisms related to inhibiting proinflammatory cytokines and inflammatory mediators that participate in the MAPK signaling pathway and promote immune function (Figure 3.).

The pro-inflammatory cytokines and inflammatory mediators are significant bioactive substances that cause inflammation. One of the markers of SARS-CoV2 infection is that high numbers of IL-6 and other inflammatory cytokines lead to cytokine release syndrome (CRS), causing ARDS (Wu et al., 2020). Therefore, developing effective inflammatory mediator antagonists could inhibit the cytokine-mediated inflammatory syndrome and provide a basis for the treatment of COVID-19. Glycyrrhizin is a well-known anti-inflammatory component in licorice. It can inhibit pro-inflammatory cytokines to regulate the inflammatory response (Michaelis et al., 2011; Bhattacharjee et al., 2012; Ishida et al., 2013; Luo et al., 2013; Fu et al., 2014a; Fu et al., 2014b; Oztanir et al., 2014; Tsao and Yin, 2015; Yu et al., 2015; Li et al., 2017). During the cause of the disease, many essential signaling cascades are dysregulated, which results in hyperinflammation, hypercytokinemia, and severe diseases, such as JAK/STAT, NF$\kappa$ B, TGF $\beta$, MAPK (Battagello et al., 2020; Catanzaro et al., 2020; Jose and Manuel, 2020; Matsuyama et al., 2020). For example, Wu et al. detected the phosphorylation status of Jak 2 and Stat 3 by specific phosphorylation antibodies. The results showed that the phosphorylation numbers of Jak2 and Stat3 increased significantly in pdx model mice, while the phosphorylation numbers of Jak2 and Stat3 decreased significantly after glycyrrhizin treatment. Glycyrrhizin can inhibit the activity of JAK/STAT signal pathway of HMGB1 upstream regulatory factor (Wu et al., 2018). Additionally, as a promising drug for treating inflammatory pain, glycyrrhizin has been shown to inhibit the high expression of lps-activated microglial high mobility group

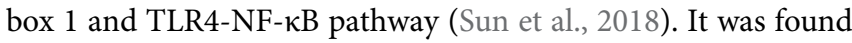
that glycyrrhizin decreased cell viability and increased apoptosis by inhibiting NF- $\kappa B$ signal pathway (Li et al., 2014). It has been reported that dipotassium glycyrrhizinate promotes the expression of miR146a and miR16 through the NF- $\kappa \mathrm{B}$ signal pathway to inhibit proliferation and increase apoptosis in 
malignant glioma cells (Bonafe et al., 2019). The above studies indicate that glycyrrhizin can effectively inhibit the inflammatory response by inhibiting the synthesis and release of proinflammatory cytokines and inflammatory mediators, and have the possibility of becoming good drugs for the treatment of COVID-19-related diseases, with potential medicinal value.

Additionally, it is indicated that other secondary metabolites of licorice also have anti-inflammatory effects (Yang et al., 2015). Inhibition of inflammation was due to inhibition of the formation of COX-2, NO, PGE 2 and cyclooxygenase activity (Tsukahara et al., 2005; Kim et al., 2014; Jia et al., 2017). The important pathway of anti-inflammatory effect was related to the mitogenactivated protein kinase (MAPK) and NF- $\kappa B$ pathways (Wang D. et al., 2020). Moreover, licochalcone A, as a phenolic ketone compound, can activate the Nuclear factor-E2 related factor2 (Nrf2) and Keap1-Nrf signaling pathways to inhibit inflammation by enhancing phosphorylation of serine 349 and the expression of P 62 (Su et al., 2018). ERK and P 38 signaling pathways may play an important role in alleviating allergic airway inflammation by licorice (Chu et al., 2013). Furthermore, studies have shown that licochalcone derivatives have specific stimulation immunity (Lee JS. et al., 2015), which can suggest another mechanism of the anti-inflammatory effects of licorice is related to promoting immune function. The above studies indicate that the secondary metabolites of licorice can also effectively inhibit the inflammatory response by inhibiting the synthesis and release of pro-inflammatory cytokines and inflammatory mediators, and the regulation of relevant immune system functions is also one of the potential mechanisms of anti-inflammatory effect, with potential medicinal value.

It has been reported that licorice protects against inflammatory diseases through other anti-inflammatory mechanisms. For instance, Broncho alveolar lavage fluid (BALF) cells of COVID-19 patients were analyzed by transcriptome sequence. It was shown that chemokines such as CXCL10 and CCL-2 were released in large quantities upon SARS-CoV2 infection (Xiong et al., 2020). The administration of 3,10 , and $30 \mathrm{mg} / \mathrm{kg}$ licorice flavonoids (LF) significantly reduced the LPS-induced inflammatory cells, including neutrophils, macrophages and lymphocytes accumulation in bronchoalveolar lavage fluids (BALF), among these inflammatory cells, LF predominately inhibited neutrophil infiltration, and the maximal effect $(30 \mathrm{mg} / \mathrm{kg})$ was as comparable as dexamethasone treatment at $1 \mathrm{mg} / \mathrm{kg}$. Consistent with its effects on neutrophil infiltration, LF treatment significantly increased LPS-induced BALF superoxide dismutase activity, and significantly decreased lung myeloperoxidase activity as well (Xie et al., 2009). Leung reviewed that the higher numbers of ACE2 in the respiratory tract of patients with chronic obstructive pulmonary disease (COPD) may increase their risk of the COVID-19 infection (Leung et al., 2020). COPD is a type of pneumonia caused by toxic particles such as cigarette smoke, fly ash, and diesel exhaust particles, which leads to severe diseases, such as chronic bronchitis and pulmonary dysfunction. Kim combined oral Glycyrrhiza glabra L. and Acorus tatarinowii to treat COPD. The results indicated that lung tissue pathological injury could be alleviated, and inhibit neutrophil airway inflammation more effectively by blocking the IL-17/STAT-3 pathway and regulating the expression of CXCL-2 and inflammatory cytokines (Kim et al., 2020). Additionally, 3, 10 , and $30 \mathrm{mg} / \mathrm{kg}$ liquiritin apioside (LA) can inhibit TGF- $\beta$ and TNF- $\alpha$ expression and increase anti-oxidative levels of GSH, which suggests that LA has a protective effect on pulmonary epithelial cell injury in COPD (Guan et al., 2012). Also, isoliquiritin, liquiritigenin, and isoliquiritigenin can inhibit fatty hepatitis and obesity (Kim YW. et al., 2011; Ahn et al., 2013). The mechanism involves inhibiting the inflammatory response of mouse macrophages induced by lipopolysaccharide (LPS) by inhibiting mRNA expression, iNOS and COX-2 protein, which provides a clinical reference point regarding COVID-19 patients with chronic diseases. In addition, in vitro studies have indicated that licorice was effective in combination with other herbs could decrease a few classical cytokines including TNF- $\alpha$, IL-1 $\beta$, MCP-1, and IFN. The levels of cytokines were back to normal, indicating that licorice composed with other herbs helps reduce the inflammatory level (Wang et al., 2021).

The above results show that licorice can play an antiinflammatory role by inhibiting pro-inflammatory cytokines and inflammatory mediators, participating in MAPK-related signaling pathways and promoting immune function during COVID-19 treatment, thus inhibiting inflammation and the occurrence of high inflammatory response or cytokine storm syndrome (Wang et al., 2015). Although pharmacodynamic mechanisms and clinical studies of licorice are being discovered and applied, its curative effect needs to be further studied. Therefore, researchers can rely on the studies of COVID19 combined with the aldosterone-like skeleton structure and anti-inflammatory solid effect of licorice to provide a more reliable basis for potential treatment in the future.

\section{ACE2 Inhibition}

ACE2 is an indispensable protein that regulates the conversion of Ang I and Ang II into Ang 1-9 and Ang 1-7 by regulating the Ang II-Ang (1-7)-mAs axis and renin-angiotensin system, which protects the lung from ARDS and maintains normal cardiovascular and renal function. Ang II-Ang (1-7)-mAs axis, has been suggestive of potential therapy to treat inflammatory diseases, such as lung disease, cancer, diabetes, and hypertension (Fang et al., 2020). Studies have been completed to establish the ability of COVID-19 to invade and enter host cells, which mainly occurs through a spike protein in its structure along with ACE2 as the receptor (Lan et al., 2020; Zhang et al., 2020). Additionally, ACE2 is widely expressed in the respiratory tract, intestinal tract, kidney, immune cells, pancreas, arterial and venous endothelium, which may explain the origin of the main clinical symptoms of COVID-19 (Gong et al., 2012). SARS-CoV2 combined with ACE2 destroys the balance between Ang I/Ang II, and Ang (1-9)/Ang (1-7) and also increases free radicals, which leads to organ damage. Similar to SARS-CoV, SARS-CoV2 may have a high affinity for ACE2 and can infect cells through the ACE2 receptor (Xu et al., 2020). However, the expression level of ACE2 receptor differs across organ and tissue types, and ACE2 protein is highly expressed in alveolar epithelial cells and intestinal 


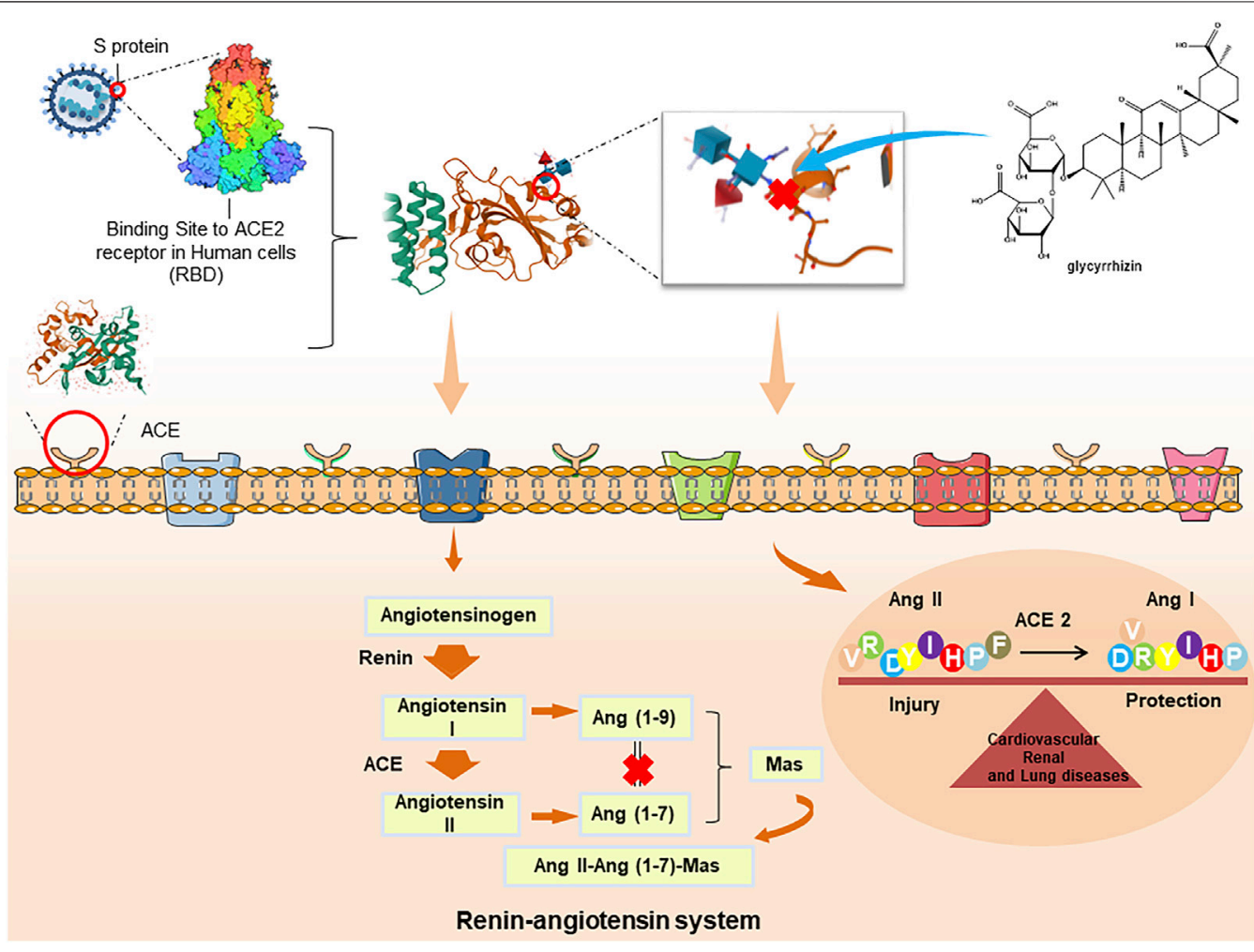

FIGURE 4 | Interaction between SARS-CoV2 and ACE2 under the action of licorice.

epithelial cells. This is similar to the symptoms of diarrhea and lung disease (Hamming et al., 2004). When SARS-CoV2 enters the human body, the increase in the level of Ang II stimulates angiotensin II type 1 receptor and then increases the permeability of pulmonary capillaries, leading to acute lung injury pulmonary edema and pulmonary failure. Subsequently, the virus could continue to infect the heart, liver, and kidney through the circulation of ACE2 in the blood, further triggering excessive immune responses such as Th1 and Th2 cell imbalance and producing in large numbers inflammatory cytokines. Then, the cytokine storm would eventually lead to multiple organ dysfunction syndromes (Qiao et al., 2020).

Recent studies showed that both SARS-CoV2 and SARS coronavirus enter the cells via the ACE2 receptor, and glycyrrhizin can significantly bind to ACE2, which is worthy of further study of its potential anti-COVID-19 effects, and results showed that glycyrrhizin has no cell toxicity to mouse aorta smooth muscle cells even at high concentrations $(100 \mu \mathrm{M})$ (Yu et al., 2020). The mechanism of glycyrrhizin against respiratory viruses may be stabilizing the SARS-COV2-S-RBDACE-2 complex, inhibiting the 3 CL hydrolase of COVID-19, and inhibiting the protein synthesis of the virus, which inhibits virus replication and may also be related to the improvement of inhibition of inflammation, immune regulation, up-regulation of NO expression, and protection of the host (Figure 4.). Moreover, in SARS-CoV2 infection, ACE 2 may aggravate the disease by activating NLRP3 inflammatory corpuscles in renal tubular epithelial cells catalyzed by the renin-angiotensin system
(Wen et al., 2016). Shubin used the NLRP3 inflammatory body activation model to explore the regulatory effect of licochalcone A on the NLRP3 inflammatory body and its preliminary mechanism. Results showed that licochalcone A could inhibit pro-caspase-1 splicing, block caspase p20-mediated shear maturation of pro-IL-1 $\beta$, and ultimately inhibit the immuneinflammatory response mediated by NLRP3 inflammatory bodies (Shubin et al., 2018). These results provide a basis for licorice in treating COVID-19 and NLRP3 inflammatory body-related diseases (Qiao et al., 2020). The above studies indicate that glycyrrhizin and the secondary metabolites of licorice can effectively inhibit the inflammatory response by inhibiting the synthesis and release of ACE 2, and have the possibility of becoming a good drug for the treatment of COVID-19-related diseases, with potential medicinal value. Licorice has the advantage of inhibiting ACE 2, but the mechanism of inhibiting ACE 2 has not been fully elucidated, and further studies are needed to promote the development of new drugs.

But it is well known that licorice is also active against many other viruses which not interact with ACE2. Recently, it is important to notice that glycyrrhizin and its metabolite 18$\beta$-glycyrrhetinic acid as the best ligand have shown a strong binding affinity of five SARS- CoV2 proteins, SARS-CoV2 protein targets include Main protease, Papain-like protease, RNA-dependent RNA polymerase, Spike glycoprotein, Helicase, and E-Channel protein (Rehman et al., 2021). Among them, E-Channel protein shares striking functional similarities in different coronaviruses, including SARS-CoV 
TABLE 2 | Antiviral active components and their possible mechanism of virus prevention.

\begin{tabular}{|c|c|c|c|}
\hline Component & Antiviral mechanism & Virus type & References \\
\hline \multirow[t]{6}{*}{ Glycyrrhizin } & Blocking $\mid \kappa B$ & CVB3 & Zhang et al. (2012) \\
\hline & Activating $T$ lymphocyte proliferation & $\mathrm{DHV}$ & Soufy et al. (2012) \\
\hline & Cutting adhesion force and stress between PMN and CCEC. & HSV & Huang et al. (2012) \\
\hline & Reducing H5N1-induced production of CCL5, IL-6, and restraining H5N1-induced apoptosis & H5N1 & Michaelis et al. (2010) \\
\hline & Deactivating CVA16, inhibiting the virus to exertanti-EV-71 effect & CVA16, EV71 & Michaelis et al. (2010); Wang et al. (2013a) \\
\hline & Stimulating IFN secretion, inhibiting virus attachment, and internalization & HRSV & Matsumoto et al. (2013) \\
\hline
\end{tabular}

and MERS-CoV. In addition to the essential roles of 2-E channel have been found that deletion of $\mathrm{E}$ channel results in attenuating SARS-CoV pathogenesis. Beyond that, E channel was also found to participate in MERS-CoV assembling, virion release, and pathogenesis. Thus, the small molecules targeting SARS-CoV2 envelope protein could also be potential broad-spectrum anticoronavirus drugs, such as an inhibitor of E protein (Tomar et al., 2021; Wang et al., 2021).

In summary, licorice may directly or indirectly protect target organs by inhibiting the binding of the virus to ACE2, antioxidant, and anti-fibrosis effects (Ming et al., 2020). The pharmacodynamic mechanisms and clinical studies of licorice are being discovered and applied, it needs to be further studied in the treatment of COVID-19. In the future, researchers can conduct further studies of ACE inhibition on glycyrrhizin, which could lead to the development of glycyrrhizin as a potential antiviral medicine for the potential treatment of COVID-19.

\section{Antiviral Effects}

Glycyrrhizin is inhibitor of the inflammation caused by viral and bacterial infections. Since the 1970s, it has been reported that the antiviral effect of glycyrrhizin by inhibiting the replication and infection of various DNA and RNA viruses at low concentrations without affecting the activity and proliferation of normal cells (Cai et al., 2012; Duan et al., 2015; Feng Yeh et al., 2013; Hardy et al., 2012; Matsumoto et al., 2013), or significantly inhibiting virus proliferation by activating the immune function. In vitro experiments showed that glycyrrhizin has strong anti-influenza effect by effectively inhibiting the replication $\left(\mathrm{IC}_{50}=0.27 \mathrm{mg} / \mathrm{ml}\right)$ of SARS associated coronavirus strains, interfered with the cycle of adsorption, and osmotic replication of several viruses (Adianti et al., 2014; Ashfaq et al., 2011; Baltina et al., 2019; Feng Yeh et al., 2013; Huang et al., 2012; Matsumoto et al., 2013; Nomura et al., 2019; Sakai-Sugino et al., 2017; Song et al., 2014; Soufy et al., 2012; Sun et al., 2019; Wang J. et al., 2013; Zhang et al., 2012; Sun et al., 2019) against several enveloped viruses (such as EBV, HAV, HBV, HCV, HIV, HRSV, VSV, VZV) and influenza viruses including H1N1 and H5N1 (Baltina et al., 2015; Michaelis et al., 2011; Michaelis et al., 2010). The basic of these effects could be attributed to the inhibition of expression and replication of viral genes, reduction of stress, adhesion, and the binding of HMGB 1 to DNA (Moisy et al., 2012). It could also relate to serum albumin binding (Wang et al., 2020a; Wang et al., 2020b; Wang H. et al., 2020), inhibit host cell apoptosis (Wang et al., 2015) or enhance the activity of host cells (Table 2). Another widely discussed mechanism of glycyrrhizin activity is the inhibiting or changing of virus membrane fusion with host membrane (Bailly and Vergoten, 2020; Chrzanowski et al., 2021).

According to recent studies, the binding of glycyrrhizin and ACE2 can effectively prevent COVID-19 infection, implying that glycyrrhizin can to bind to ACE2 at its binding sites (Arg-393, Arg-559, Asp-30 and Gln-388), which suggests that glycyrrhizin has potential binding for ACE2 (Chen and Du, 2020a). For instance, Ma used the network pharmacology approach, molecular docking, and other technologies. It is important to notice that glycyrrhizin can be used as a 3 CL hydrolase inhibitor of SARS-COV2 through a series of molecular reactions in the cell membrane and cytoplasm, such as ATP binding, protein binding and enzymatic reactions to participate in the regulation and signal transduction of cell biological processes with multichannels cooperating to show anti-COVID-19 effect (Ma et al., 2020). Nonetheless, Zhou showed that glycyrrhizin could strongly combine with SARS-COV2-S-RBD-ACE2 binding domain with SARS-COV2-S-RBD-ACE2, further, affect its stability to produce anti-SARS-COV2 (Zhou S. et al., 2020). Based on combining computer-aided drug design and biological verification, glycyrrhizin has been reported as a potential antiviral molecule. Using surface plasmon resonance technique and live cell real-time protein interaction detection technique, it was found that glycyrrhizin could directly bind to the spike protein of SARS-CoV2, thus affecting the interaction between SARS-CoV2 and ACE2 (Yu et al., 2020). Owing to low toxicity, its potential interaction with ACE2, and its antiviral effect on SARS, it is of great necessity to further study antiviral effect of glycyrrhizin. Numbers of studies indicate the promise of using various inhibitors of the fusion of viral particles with the cell plasma membrane (Tang et al., 2020), the membrane modifying activity of glycyrrhizin is described in a number of physicochemical studies and reviews. Selyutina hypothesized that the increased bioavailability of the drug by glycyrrhizin is not only due to increased solubility, but also to enhancement of drug permeability through cell membranes (Selyutina et al., 2016a). Glycyrrhizin was shown to increase the permeability (about 60\%) and to decrease elasticity modulus of cell membranes (by an order of magnitude) even in micromolar concentrations (Selyutina et al., 2016b). The most intriguing feature of glycyrrhizin which might be the key factor in its therapeutic activity is the ability of glycyrrhizin to incorporate into the lipid bilayer and to increase the membrane fluidity and permeability (Selyutina and Polyakov, 2019). Furthermore, glycyrrhizin derivatives also show anti-SARS-CoV effect, which could be significantly improved by introducing 2 - 
TABLE 3 | Antibacterial and antifungal mechanism of licorice.

\begin{tabular}{|c|c|c|c|c|}
\hline Component & Antibacterial/antifungal mechanism & $\begin{array}{c}\text { Type of } \\
\text { microorganism }\end{array}$ & $\begin{array}{c}\text { The range of } \\
\text { the } \\
\text { concentrations }\end{array}$ & References \\
\hline Glycyrrhizin & $\begin{array}{l}\text { Reducing the expression of key genes SaeR and } \\
\text { Hla of MRSA virulence } \\
\text { Inhibiting pathogenic bacteria and reducing the } \\
\text { bacterial gene expression }\end{array}$ & $\begin{array}{l}\text { S. aureus; } \\
\text { Enterococcus }\end{array}$ & $\begin{array}{l}\text { MIC: } 62.5 \mu \mathrm{g} / \mathrm{ml} \\
\text { MIC: } 4-8 \mathrm{mg} / \mathrm{ml}\end{array}$ & $\begin{array}{l}\text { Long et al. (2013); Schmidt } \\
\text { et al., 2016) }\end{array}$ \\
\hline licochalcone $\mathrm{A}$ and glabridin & $\begin{array}{l}\text { Restraining biofilm formation and preventing } \\
\text { yeast-hyphal transition }\end{array}$ & C. albicans & $\begin{array}{l}\text { MIC: } \\
6.25-12.5 \mu \mathrm{g} / \mathrm{ml}\end{array}$ & Messier Grenier, (2011) \\
\hline licochalcone E & Reducing the production of $\alpha$-toxin & S. aureus & - & Zhou et al. (2012) \\
\hline Liquiritigenin & Decreasing the production of $\alpha$-hemolysin & S. aureus & MIC: $512 \mu \mathrm{g} / \mathrm{ml}$ & Dai et al. (2013) \\
\hline glycyrrhizin and its derivatives & $\begin{array}{l}\text { Inhibiting nutrient acquisition and affecting } \\
\text { bacterial metabolism }\end{array}$ & S. aureus & $\begin{array}{l}\text { Above MIC: } \\
128 \mathrm{mg} / \mathrm{L}\end{array}$ & Oyama et al. (2016) \\
\hline isoliquiritigenin and liquiritigenin & Reducing the production of bacterial toxins & S. aureus & MIC: $50-100 \mu \mathrm{g} / \mathrm{ml}$ & Gaur et al. (2016) \\
\hline licochalcone A & $\begin{array}{l}\text { Inhibiting fungal activity especially in the } \\
\text { glyoxylate cycle }\end{array}$ & T. rubrum & MIC: $11.52 \mu \mathrm{g} / \mathrm{ml}$ & Cantelli et al. (2017) \\
\hline $\begin{array}{l}\text { isobavachalcone, 4-hydroxycarotene, } \\
\text { and kanzonol C }\end{array}$ & $\begin{array}{l}\text { Inhibiting at various extents the reverse } \\
\text { transcriptase activity }\end{array}$ & D. barteri & $\mathrm{MIC}<10 \mu \mathrm{g} / \mathrm{ml}$ & Kuete et al. (2010) \\
\hline licochalcone E & Reducing the production of $a$-toxin & S. aureus & MIC: 0.3 mg/ml & Mbaveng et al. (2008) \\
\hline Glabridin & $\begin{array}{l}\text { Guiding fractionation against selected fungal } \\
\text { strains }\end{array}$ & C. albicans & $\begin{array}{l}\text { MIC: } \\
31.25-250 \mathrm{mg} / \mathrm{ml}\end{array}$ & Fatima et al. (2009) \\
\hline
\end{tabular}

acetylamino- $\beta$-D-glucopyranosamine into the glycoside chain. The above studies indicate that glycyrrhizin can effectively protect host cells from viral infection by inhibiting the viral replication cycle and has the possibility of becoming a good drug for the treatment of COVID-19-related diseases, with potential medicinal value.

Also, plenty of LF has broad-spectrum antiviral effects by inhibiting the expression and replication of viral genes and inducing apoptosis of related cells. For example, licochalcone $A$ and other chalcones, liquiritigenin, liquitin7-apigenin, isoliquiritigenin, glycyrrhizylcoumarin, glycyrrhizin opioid glycoside, quercetin, neo-isopenicillin, iso-oligosaccharide, and kanzonol Y have strong inhibitory effects on HCV (Adianti et al., 2014), HIV (Fukuchi et al., 2016), HSV-1 (Lee et al., 2017), EBV (Lee M. et al., 2015), EBOV (Fu et al., 2016), DENV (Powers and Setzer, 2016) and H1N1, influenza viruses including the new H1N1 (Dao et al., 2011). Zhu showed that glycyrrhizin can effectively inhibit SARS-CoV2, and the mechanism may be by imitating type I interferon to exert antiviral effect (ZhuJie et al., 2020). All the above studies indicate that LF can effectively exert broad-spectrum antiviral activity by inhibiting the expression of viral genes and have the possibility of becoming a good drug for the treatment of COVID-19-related diseases, with potential medicinal value.

In conclusion, these results provide evidence that a number of mechanisms could cause the beneficial effects of the active components of licorice. The basic of these effects could be attributed to the stabilization of SARS-CoV2-S-RBD-ACE2 complex and the inhibition of 3CL hydrolase of SARS-CoV2, as well as the inhibition of protein synthesis of the virus, resulting in the inhibition of viral replication. It may also be related to the improvement of immune regulation, up-regulation of NO expression, inhibition of platelet aggregation, inflammatory response and protection of host, which suggests it may be useful to develop an alternative medicine for adjuvant treating
COVID-19 to some extent. However, these studies are preliminary clinical observations without rigorous trial design, and need to be verified by a large number of clinical observations with rigorous trial design in the future.

\section{Antibacterial and Antifungal Effects}

Common in patients with COVID-19 are secondary bacterial coinfection. Thus, it is of great necessity to provide antibiotic treatment for some patients who are infected with bacteria. In addition to the primary biological activities before mentioned, licorice have antiviral effects and broad-spectrum antibacterial effects, so it may be an effective treatment for infections or secondary infections in patients with COVID-19. Studies in large numbers have indicated that licorice and glycyrrhizin, liquiritigenin, isoliquiritigenin and some flavonoids have strong antibacterial effects against Gram-positive cocci, Grampositive bacteria, and Bacillus cereus (Rodino et al., 2015). The mechanism of action is related to reducing the expression of bacterial genes, the production of bacterial toxins, and inhibiting bacterial growth (Messier and Grenier, 2011; Zhou et al., 2012; Dai et al., 2013; Long et al., 2013) (Table 3).

Much of researches in antibacterial effect have found that licorice can exert antibacterial effects by inhibiting pathogenic bacteria and reducing the bacterial gene expression. For instance, $2.4 \mathrm{mM}$ glycyrrhizin decreased the minimum inhibitory concentration (MIC) of gentamicin from $>8 \mathrm{mg} / \mathrm{L}$ to $\leq 0.125 \mathrm{mg} / \mathrm{L}$ (Schmidt et al., 2016). Long investigated the antibacterial effect of glycyrrhizin on methicillin-resistant Staphylococcus aureus (MRSA) in a mouse model of skin infection. The results indicated that a high concentration of glycyrrhizin had a bactericidal effect on MRSA. Recently, glycyrrhizin could reduce the expression of key virulence genes of MRSA with sublethal doses, such as Hla and SaeR (Long et al., 2013). The above studies indicate that glycyrrhizin can effectively play an antibacterial role by 
inhibiting bacterial gene expression and has the possibility of becoming a good drug for the treatment of COVID-19-related diseases, with potential medicinal value.

Other studies have shown that the inhibition of bacterial growth is also one of the mechanisms of the antibacterial effect of licorice. As an example, it has been shown that the antibacterial effect of glycyrrhizin and its derivatives in 50 clinical patients determines the MIC of glycyrrhizin, dipotassium glycyrrhizinate, disodium succinylglycyrrhizin, disodium glycyrrhizin, stearylglycyrrhetinate, and glycyrrhetinyl stearate. The results indicated that compared with other medications, glycyrrhizin, and disodium succinyl glycyrrhizin had a stronger antibacterial effect by inhibiting amino acid metabolism and carbohydrate (Oyama et al., 2016). More importantly, licorice can also exert its antibacterial effect by inhibiting the growth of bacteria. As a typical example, liquiritigenin and isoliquiritigenin have significant inhibitory effects on Ralstoniasolanacearum and MRSA (Gaur et al., 2016). Additionally, liquiritigenin and isoliquiritigenin can help protect human lung cells from MRSA infection by reducing the production of bacterial toxins (Dai et al., 2013; Gaur et al., 2016). The above studies indicated that glycyrrhizin and the secondary metabolites of licorice can effectively inhibit bacterial fungal activation and have the possibility of becoming good drugs for the treatment of COVID-19-related diseases, with potential medicinal value.

In a retrospective analysis published in the Lancet, the current situation of bacterial and fungal infections in 99 patients with COVID-19 was described for the first time. Among them, 5 cases were suspected to be complicated with fungal infection and 1 case with bacterial infection (Chen et al., 2020b). Based on the experience of SARS in 2003 and the cases of invasive Aspergillus infection secondary to severe influenza, viral infection significantly increased the possibility of concurrent or secondary fungal infection and the mortality of patients (Hong et al., 2004; Vanderbeke et al., 2018). Some flavonoids have a strong antimicrobial effect against fungal and bacterial infections, which may be a potential treatment for severe pulmonary infections, potentially treating severe pulmonary infections. For instance, licochalcone A also has antimicrobial effects by inhibiting microbial growth, reducing the expression of microbial genes and the production of microbial toxins (Tsukiyama et al., 2002; Zhou et al., 2012; Hao et al., 2013). In screening new biomolecules with antifungal activity, licochalcone A showed good antifungal activity with a MIC of $11.52 \mu \mathrm{M}$ against Trichomonas rubrum. Additionally, human keratinocytes' cell activity was determined, and the $\mathrm{IC}_{50}$ value of licochalcone $\mathrm{A}$ was $30.40 \mu \mathrm{M}$, which suggests moderate cytotoxicity to this human cell line (Cantelli et al., 2017). Licochalcone A also exhibited activity against yeast-like fungi such as $C$. albicans at concentrations of 6.25 to $12.5 \mu \mathrm{g} / \mathrm{ml}$ (Messier and Grenier, 2011). Similarly, isobavachalcone, 4-hydroxycarotene, and kanzonol C have antimicrobial effects against Gram-positive and Gramnegative bacteria. The mechanism of action is to inhibit the growth of four species of fungi, six species of Gram-positive bacteria and seven species of Gram-negative bacteria (Kuete et al., 2010). Additionally, licochalcone $\mathrm{E}$ has an antimicrobial effect on
MRSA by reducing the production of a-toxin. Consequently, it can be used to chemically synthesize new anti-Staphylococcus aureus compounds to reduce the production of toxins in MRSA (Mbaveng et al., 2008). Glabridin is the active component of Glycyrrhiza glabra L. root. It also inhibits yeast, Candida albicans, and filamentous fungi. The results showed that glabridin showed drug-resistant modification activity against Candida albicans mutants, and the MIC was $31.25-250 \mu \mathrm{g} / \mathrm{mL}$. This is the first time to report its activity against drug-resistant mutants (Fatima et al., 2009).

From the aforementioned studies, it can be concluded that these components can reduce the expression of microbial genes, the production of microbial toxins, and inhibit microbial growth to treat related diseases. Therefore, systematic research on the antibacterial and antifungal mechanism of licorice and further developing new antimicrobial agents may provide a basis to treat COVID-19. It is suggested that the use of licorice as a complementary treatment for COVID-19 can protect patients from a bacterial infection that usually occurs after a viral infection which is the main cause for lung disease.

\section{Immunomodulatory Effects}

The immune status of human body is closely related to the occurrence, development and prognosis of COVID-19 infection. Clinical studies have revealed that SARS-COV2 induces excessive activation of immune cells in the lungs, producing a host of inflammatory factors to form a cytokine storm, and accumulates plenty of immune cells, tissue fluid gathered in the lungs, affects the gas exchange between alveoli and capillaries, leading to hypoxemia, acute respiratory distress, and even respiratory failure. It has been recognized that effective physical immune responses play a crucial role in virus elimination and disease prevention (Chen et al., 2020b). Recently, people pour attention into the immunomodulatory effect of licorice. It has been reported that licorice not only improves immunity against virus indirectly, but also reduces the degree of inflammatory reaction and protects organ function. Licorice has the advantages of less side effects, multi-targets, multi-levels and so on. The mechanism of the regulation of cytokine release, the activity of immune cells and pulmonary vascular permeability, and influence the process and aspects of the cytokine storm (Hendricks et al., 2012; Wang Z. et al., 2013; Ma et al., 2013; Fontes et al., 2014).

Glycyrrhizin is an effective immunomodulator that regulates the immune system by acting on themitogen-activated protein kinase (MAPK) signaling pathway, Toll-like receptor signal pathway, and stimulates immune cell activity to play an immunomodulatory role, such as macrophages, NK cells. (Bordbar et al., 2012; Gong et al., 2012; Kim et al., 2012; Zhao et al., 2016; Wang B. et al., 2018; Wang BK. et al., 2018). For example, glycyrrhizin combined with the fucosemannose ligand could inhibit the production of IL-10 in activated macrophages, enhance IL-12, and the immunomodulatory effect of glycoprotein on macrophages (Namdar Ahmadabad et al., 2020). These results suggest that glycyrrhizin can stimulate immune cells through multiple targets and pathways to regulate immune function. 
Studies have shown that glycyrrhizin can enhance the immune status by regulating the proliferation of Treg cells (Hendricks et al., 2012; Mitra Mazumder et al., 2012; Han et al., 2017; Wang et al., 2017). Among them, Treg cells inhibit T cells, antigenpresenting cells, and reduce the production of pro-inflammatory cytokines and antibody secretion, which can reflect up-regulation of immune function. Therefore, it is of great necessity that Treg cells prevent autoimmunity and control the immune response. Consequently, selectively increasing Treg cells in vivo have extensive therapeutic significance for autoimmune and inflammatory diseases. Other studies have shown that isoliquiritigenin and naringenin are also effective components that regulate the immune response induced and suppressed by Treg cells, and can significantly promote the proliferation of Treg cells in mice and that these two flavonoids can induce more Treg cells at lower doses than glycyrrhizin (Guo et al., 2015). These results suggest that glycyrrhizin can enhance immune function by regulating immune cells.

Licorice polysaccharide is a good immune enhancer, which can significantly improve the specific and non-specific immunity of the body, and activate the immune system by promoting the mature differentiation and reproduction of immune cells (such as lymphocytes and macrophages). For example, Ayeka reviewed that licorice polysaccharide can regulate the immunity of tumorbearing $\mathrm{BALB} / \mathrm{c}$ mice, significantly inhibit tumor growth, and increase the index of immune organs, such as $\mathrm{CD}^{+}$and $\mathrm{CD} 8^{+}$ $\mathrm{T}$ cells compared to a saline group with a significant increase and decrease respectively (Ayeka et al., 2017). Min found that licorice polysaccharide was given to mice for 14 days. The delayed type hypersensitivity induced by dinitrofluorobenzene in mice was determined. The contents of IL- 2 and TNF- $\alpha$ in blood and the effect of licorice polysaccharide on cellular immune function of mice were detected by radioimmunoassay. The results showed that licorice polysaccharide could enhance the delayed type hypersensitiity reaction and increase the contents of IL-2 and TNF- $\alpha$ in blood (Min et al., 2009). These results suggest that licorice polysaccharide can enhance the immune function of mice by promoting the maturation and differentiation of immune cells.

The above results demonstrate the immunomodulatory effects of licorice, which suggests that it can be used as a candidate for the development of new immunomodulatory medicine. However, the study of immunomodulatory effects of licorice is limited. Therefore, further reliable data are needed to confirm the immunomodulatory effects of licorice.

\section{Anti-Pulmonary Fibrosis Effects}

Following effective, comprehensive treatment, the pulmonary lesions of COVID-19 patients usually recover on their own. However, some COVID-19 patients develop pulmonary fibrosis after rehabilitation (Matsuyama et al., 2020). Hence, it is worth pouring attention to the occurrence of $\mathrm{PF}$ in patients with COVID-19, given that early interventions may help avoid this condition. PF is a severe lung disease characterized by excessive accumulation of extracellular matrix (ECM) (Rajasekaran et al., 2015; Bardou et al., 2016). Inflammatory cell infiltration, hyperemia, and edema are predominant in the early stage, followed by alveolar epithelial cells, AEC injury, and
ECM-producing cells, including excessive production of ECM, abnormal proliferation of fibroblasts $(\mathrm{Fb})$, which results in progressive scarring and loss of pulmonary function.

Licorice also has a protective effect on lung tissue (Liu et al., 2019). On the one hand, glycyrrhizin can reduce local fibrosis and pulmonary edema induced by bleomycin, slightly thicken the pulmonary interstitium, and significantly reduce the content of Col-I and Hyp in lung tissue (Gao et al., 2015). However, glycyrrhizin can down-regulates AEC markers (E-cadherin) in lung tissue, significantly inhibited the increase of malondialdehyde, myeloperoxidase, transforming growth factor-Smad1, p-Smad3, p- $\beta 2$ and interstitial cell markers induced by bleomycin (Gao et al., 2015). Li showed that glycyrrhizin can reduce bleomycin-induced inflammation and collagen deposition in the lungs of mice. The anti-PF effects of glycyrrhizin are considered related to phenotypic regulation and deviation of mononuclear macrophages and down-regulation of TGF- $\beta 1$ expression in lung tissue (Li et al., 2017). In clinical studies, intravenous infusion of glycyrrhizin Diamine $(300 \mathrm{mg} /$ day for 4 weeks) combined with its capsule $(150 \mathrm{mg} /$ day for 5 months) significantly reduced the numbers of type III procollagen and serum hyaluronic acid in patients with PF, with mild side effects, such as elevated blood pressure, edema, palpitation (Hsieh et al., 2012).

The above results suggest that licorice can improve bleomycininduced $\mathrm{PF}$, inflammatory reaction, oxidative stress, downregulate the TGF- $\beta$ signaling pathway and epithelialmesenchymal transition (EMT), inhibit $\mathrm{Fb}$ migration and proliferation, promote $\mathrm{Fb}$ apoptosis, especially in ECMinduced PF, and that its mechanism is closely related to its anti-inflammatory effect.

\section{Protection of Other Organs}

A recent study published in the Lancet found that blood vessel is a direct target of SARS-CoV2 (Varga et al., 2020). If a blood clot, formed by the damage to the inner wall of the blood vessel, it will become loose as the blood circulates to the brain and lungs, eventually leading to a stroke or pulmonary embolism in patients with COVID-19. Licorice can protect vascular endothelial cells by inhibiting the adhesion, migration, and proliferation of related endothelial cells (Kim JM. et al., 2011; Tan et al., 2014).

As mentioned above, there is an increased prevalence and mortality due to pneumonia in COVID-19 patients with chronic diseases such as diabetes (McDonald et al., 2014; PearsonStuttard et al., 2016; Li et al., 2019). Studies have confirmed that liquiritigenin, isoliquiritigenin, licochalcone $\mathrm{A}$, isobavachalone, glabridin, and kanzonol $\mathrm{C}$ have protective effects on the heart, liver, and kidney (Park et al., 2012; Wu et al., 2013; Gaur et al., 2014; Yao et al., 2014). The mechanism of the inhibition of the MAPK signaling pathway, NF- $\kappa \mathrm{B}$ signaling pathway, has a protective effect on myocardial fibrosis. Additionally, flavonoids are inhibitors used to treat obesity, such as licochalcone $\mathrm{A}$, isobavachalone and kanzonol $\mathrm{C}$ (Zhang et al., 2016; Xie, 2017; Lee et al., 2018).

The above results show that patients with COVID-19, who may have different degrees of multiple organ failure, such as lung, heart, liver, and kidney diseases, could benefit from the wide 
TABLE 4 | Clinical studies on the potential treatment of COVID-19 with licorice.

Medicine

Abidol combined with

Glycyrrhizin Diamine Entericcoated Capsules

Diammonium Glycyrrhizinate

Diammonium Glycyrrhizinate

Lianhuaqingwen capsule

Lianhuaqingwen capsule Vero cells

104 novel coronavirus pneumonia patients (60 males and 45 females)

284 patients (142 each in treatment and control group)
Randomized, Control and observation group

Randomized, Control and observation group

2 weeks

\section{$78.26 \%$}

ate markedly effective rate and total effective rate of the observation group were 19.23, 28.85 and $61.54 \%$ respectively, which were significantly higher than those of the control group (7.69, 17.31 and 40.38\%) $p<$ 0.05). After treatment, the average levels of serum CRP, IL-4 and TNF- $\alpha$ water $\mathrm{k}$ in the observation group were significantly lower than those in the control group, while the levels of $\mathrm{CD}^{+}, \mathrm{CD}^{+}, \mathrm{CD}^{+}$and $\mathrm{CD} 4^{+} / \mathrm{CD}^{+}$in the observation group were significantly higher than those in the control group. The incidence of adverse reactions in the observation group (15.38\%) was significantly lower than that in the control group (28.85\%) ( $p<0.05)$

72-96 h Expression of viral antigens was much lower in cultures treated with $1,000 \mathrm{mg} / \mathrm{L}$ of glycyrhizin than in any other culture; high concentrations of glycyrthizin $(4,000 \mathrm{mg} / \mathrm{L})$ completely blocked replication of the virus The recovery rate was significantly higher in treatment group as compared with control group ( 91.5 vs. $82.4 \%, p=0.022$ ). The median time to symptom recovery was markedly shorter in treatment group (median: 7 vs. 10 days, $p<0.001$ ). Time to recovery of fever ( 2 vs. 3 days), fatigue ( 3 vs. 6 days) and coughing ( 7 vs. 10 days) was also significantly shorter in treatment group (all $p<0.001$ ). The rate of improvement in chest computed tomographic manifestations (83.8 vs. $64.1 \%$, $p<0.001)$ and clinical cure (78.9 vs. $66.2 \%$, $p=0.017$ ) was also higher in treatment group. However, both groups did not differ in the rate of conversion to severe cases or viral assay findings (both $p>0.05$ )

42 patients ( 21 subjects in the treatment group and 21 subjects in the control group)
Randomized, Control and observation group
Compared with the control group, patients in the treatment group had the higher clinical effect, including the disappearance rate of fever (85.7 vs. $57.1 \%, \chi^{2}=4.200, p=0.040$ ), the disappearance rate of cough (46.7 vs. $5.6 \%, p=0.012)$, the disappearance rate expectoration (64.3 vs. $9.1 \%, p=0.012$ ), the disappearance rate of shortness of breath (77.8\% vs. $0, p=0.021)$, and the duration of fever $[(4.6+3.2) d$ vs. $(6.1+3.1) d, p=0.218]$
Zhou et al. (2020b)

Cinatl et al. (2003) 
range of pharmacological activities of licorice. So, based on the existing research, future studies that examine the efficacy, doseeffect relationship, action mechanism, and target, adverse reactions, and so on, could provide a safer and more reliable basis for the clinical application of treatments for COVID-19.

\section{CLINICAL STUDIES ON THE POTENTIAL TREATMENT OF COVID-19 WITH LICORICE}

Licorice can play an auxiliary role in the clinical treatment of COVID-19 and comprehensively relieve the adverse symptoms of patients (Table 4). In a clinical study, Zhou (Zhou, et al., 2020c) conducted a clinical observation on the treatment of COVID-19 patients with Glycyrrhizin Diamine. The patients in the control group were treated according to the "diagnosis and treatment of pneumonia caused by novel coronavirus (trial version 5)," and the patients in the observation group were treated with glycyrrhizin Diamine enteric-coated capsule (150 mg, 3 times/ $\mathrm{d}$, for 2 weeks). The results showed that the serum numbers of CRP, IL-4, and TNF- $\alpha$ in the observation group were significantly lower than those in the control group, while the numbers of $\mathrm{CD}^{+}, \mathrm{CD}^{+}, \mathrm{CD}^{+}, \mathrm{CD}^{+} / \mathrm{CD}^{+}$in the observation group were significantly higher than those in the control group, and the prevalence of adverse reactions [ $15.38 \%$ (8/52) vs. $28.85 \%$ (15/ $52)]$ of the observation group were significantly lower than that of the control group $(p<0.05)$. Glycyrrhizin Diamine has significant clinical efficacy and high safety in the treatment of common COVID-19 patients, which can inhibit the inflammatory reaction and improve immune function. $\mathrm{Xi}$ (Xi et al., 2020) used Abidol combined with Glycyrrhizin Diamine Enteric-coated Capsules treated COVID-19 patents. WBC count, N\%, erythrocyte sedimentation rate, PCT and other infectious indicators, CRP, IL-6 and other inflammatory indicators as well as liver and kidney function, adverse reactions and other data were collected before and after treatment. The differences of various indicators before and after treatment were analyzed to elucidate the efficacy and safety of Abidol combined with Glycyrrhizin Diamine Enteric-coated Capsules in the treatment of COVID-19. Results showed the main clinical symptoms of 46 patients were low-grade fever, cough and fatigue. Compared with that before treatment, the symptoms of patients were significantly improved after treatment $(p<0.05)$. WBC count, N\%, erythrocyte sedimentation rate and other infectious indicators were decreased, of which $\mathrm{N} \%$ had statistical significance $(p<0.05)$. Lymphocyte count was significantly increased $(p<0.05)$. CRP, IL-6, PCT and other inflammatory indicators were decreased, of which IL-6 had statistical significance $(p<0.05)$. Albumin content, ALT were significantly increased $(p<0.05)$, other liver and kidney function indicators were not significantly changed. No nausea, vomiting and other related drug adverse reactions were reported, AST, ALT increased in 3 cases, ALT alone increased in 5 cases. The overall cure rate was $63.04 \%$, and the overall response rate was $78.26 \%$. It suggested that Abidol combined with Glycyrrhizin Diamine Enteric-coated Capsule in the treatment of COVID-19 has reliable clinical efficacy, which can effectively reduce the inflammatory response in patients with fewer adverse reactions, high safety, is a feasible choice for the treatment of new coronary pneumonia. In another clinical study, Ding treated COVID-19 with Glycyrrhizin Diamine combined with troxerutin and vitamin C. The results showed that the body temperature of the patients began to drop and gradually returned to normal on the second and third day of treatment, and then all improved and recovered within 5 days (http://www.chictr.org.cn/). Additionally, some clinical studies on SARS treatment have shown that licorice has potential efficacy in the development of COVID-19 possible treatment (Cinatl et al., 2003). In 2004, it was reported that glycyrrhizin could be used in the treatment of SARS (Ling, et al., 2004; Yuping, et al., 2004). For example, Chi divided 60 cases of SARS into two groups on average: the treatment group was treated with compound glycyrrhizin, the control group was treated with conventional treatment. The appearing time, site, scope, and dynamic changes in the pulmonary lesions on chest radiograms were compared between two groups. Results showed that the average period from peak to $50 \%$ improvement of lesion in X-ray manifestations was shorter in group I than in group II. In the restoration stage, more patients had their X-ray findings absorbed in group I compared with the patients in group II. Compound glycyrrhizin had little influence on the White Blood Cells, blood sugar, and electrolytes. It showed that glycyrrhizin may be a promising medicine against SARS with fewer side effects (Chihong, et al., 2004).

At present, there are few clinical studies on licorice in the potential treatment of COVID-19, and there are many studies on the compound prescription with licorice as the main component. For example, LianhuaQingwen capsule, which is composed of Forsythia suspensa, Flos lonicerae, licorice and other 13 herbs, can inhibit virus replication, cause changes in virion shape and inhibit the expression of inflammatory factors in host cells to play the role of anti-novel coronavirus effect. The latest research shows that LianhuaQingwen capsule can inhibit the effect of COVID-19 in vitro and significantly relieve the symptoms of fever, cough, and fatigue in patients with COVID-19 (Hongrong et al., 2020). $\mathrm{Hu}$ observed the clinical efficacy of LianhuaQingwen capsule in the treatment of COVID-19. The treatment group was treated with usual treatment combined with LianhuaQingwen capsule (4 tablets, 3 times/d), while the control group was treated with usual treatment. The results showed that after 14 days of treatment in the LianhuaQingwen treatment group, the recovery rate of the LianhuaQingwen capsule treatment group was $91.5 \%$, which was significantly higher than that of the control group (82.4\%). And the median cure time for fever, fatigue, cough, and other symptoms in LianhuaQingwen capsule treatment group was significantly shortened ( $\mathrm{Hu}$ et al., 2020). LianhuaQingwen capsule can be considered to improve the clinical symptoms (fever, dry cough and fatigue) of COVID-19, which provide a basis for the application of LianhuaQingwen combined with existing techniques in the potential treatment of COVID-19. Yao observed the clinical effect of LianhuaQingwen capsule in the treatment of COVID-19. The treatment group was treated with routine treatment combined with LianhuaQingwen granule, and the control group was treated with routine treatment. The 
results showed that When compared with the control group, patients in the treatment group had higher clinical effect, including the disappearance rate of fever ( 85.7 vs. $57.1 \%, \chi^{2}=$ 4.200, $p=0.040$ ), the disappearance rate of shortness of breath (77.8\% vs. $0, p=0.021)$, and the duration of fever $[(4.6 \pm 3.2) \mathrm{d}$ vs. $(6.1 \pm 3.1) \mathrm{d}, p=0.218]$. It is suggested that the drug has a certain clinical application value in improving the symptoms of COVID19 patients, relieving the disease, and shortening the course of disease (Kaitao et al., 2020).

\section{CONCLUSION}

To sum up, licorice plays a synergistic role in regulating the symptoms of COVID-19 patients through multi-components and multi-targets, and participates in biological processes such as immunity, anti-inflammation and signal transduction, suppresses the production of cellular endotoxin, balances immunity, eliminates inflammation, avoids or alleviates inflammatory storms, and has a good clinical effect on the prevention and treatment of COVID-19. Among them, glycyrrhizin and glycyrrhetinic acid interact with ACE 2, spike protein, host transmembrane serine protease 2 and 3 chymotrypsin-like cysteine protease to alleviate the common symptoms of COVID-19 patients, such as pulmonary inflammation and liver and kidney injury. Liquiritin can relieve fever, cough, fatigue and other symptoms of COVID-19 patients to some extent by stimulating type I interferon. Oral licorice preparation (150mg/, 3 times / d for 2 weeks) could improve the symptoms of low fever, cough and fatigue in patients with mild to moderate COVID-19 (the overall effective rate $\geq 60 \%$ ) (Table 5). It is suggested that different components can play a synergistic effect on the prevention and treatment of COVID-19. The first edition of Chinese Pharmacopoeia 2020 stipulates that licorice

\section{REFERENCES}

Adianti, M., Aoki, C., Komoto, M., Deng, L., Shoji, I., Wahyuni, T. S., et al. (2014). Anti-hepatitis C Virus Compounds Obtained from Glycyrrhiza Uralensis and Other Glycyrrhiza Species. Microbiol. Immunol. 58, 180-187. doi:10.1111/ 1348-0421.12127

Ahn, J., Lee, H., Jang, J., Kim, S., and Ha, T. (2013). Anti-obesity Effects of GlabridinRich Supercritical Carbon Dioxide Extract of Licorice in High-Fat-Fed Obese Mice. Food Chem. Toxicol. 51, 439-445. doi:10.1016/j.fct.2012.08.048

Alam, P., Foudah, A. I., Zaatout, H. H., T, K. Y., and Abdel-Kader, M. S. (2017). Quantification of Glycyrrhizin Biomarker in Glycyrrhiza Glabra Rhizome and Baby Herbal Formulations by Validated Rp-Hptlc Methods. Afr. J. Tradit Complement. Altern. Med. 14, 198-205. doi:10.21010/ajtcam.v14i2.21

Altay, V., Karahan, F., Öztürk, M., Hakeem, K. R., Ilhan, E., and Erayman, M. (2016). Molecular and Ecological Investigations on the Wild Populations of Glycyrrhiza L. Taxa Distributed in the East Mediterranean Area of Turkey. J. Plant Res. 129, 1021-1032. doi:10.1007/s10265-016-0864-6

Ashfaq, U. A., Masoud, M. S., Nawaz, Z., and Riazuddin, S. (2011). Glycyrrhizin as Antiviral Agent against Hepatitis C Virus. J. Transl Med. 9, 112. doi:10.1186/ 1479-5876-9-112

Ayeka, P. A., Bian, Y., Githaiga, P. M., and Zhao, Y. (2017). The Immunomodulatory Activities of Licorice Polysaccharides (Glycyrrhiza Uralensis Fisch.) in CT 26 Tumor-Bearing Mice. BMC Complement. Altern. Med. 17, 536. doi:10.1186/s12906-017-2030-7 contains no less than $2.0 \%$ glycyrrhizin and $0.1 \% \sim 0.2 \%$ glycyrrhetinic acid. The common clinical dose of glycyrrhizin is less than $100 \mathrm{mg}$ (equivalent to $5 \mathrm{~g}$ licorice at the effective dose), and the common dose of glycyrrhetinic acid is $250 \sim 500 \mathrm{mg}$ (equivalent to $125 \sim 250 \mathrm{~g}$ licorice at the effective dose), suggesting that licorice meets the formability of the drug preparation. At the same time, it meets the requirements of conventional drug dosage and meets the needs of clinical drug use.

At present, the clinical trial of licorice on the prevention and treatment of COVID-19 is mainly based on the improvement of inflammatory factors, suggesting that licorice and its related preparations can significantly improve the increase of inflammatory factors. However, this index is not enough to make an accurate diagnosis of the clinical symptoms of patients with COVID-19, the clinical index is too single, lack of respiratory diseases, virus metastasis rate and other indicators. Therefore, for the observation of etiology and related blood test indicators (such as serological detection), the diagnostic efficiency of multi-index combined detection is very important.

At present, most of them are based on experimental basic research, so there is a lack of sufficient clinical research. It is believed that with the deepening of clinical research, its more reasonable dosage, more accurate evaluation index and mode of administration will be deeply analyzed. At the same time, it will provide the basis for the new use and clinical application of licorice.

\section{AUTHOR CONTRIBUTIONS}

LH, J-zL, Z-cX, X-fC and QS put forward the idea. Q-hZ and $\mathrm{H}-\mathrm{zH}$ together collected the materials and wrote the paper. MQ, Z-fW and D-kZ contributed to the revisions. All authors confirmed that the manuscript has been read and approved by all named authors.

Bailly, C., and Vergoten, G. (2020). Glycyrrhizin: An Alternative Drug for the Treatment of COVID-19 Infection and the Associated Respiratory Syndrome? Pharmacol. Ther. 214, 107618. doi:10.1016/j.pharmthera.2020.107618

Baltina, L. A., Tasi, Y. T., Huang, S. H., Lai, H. C., Baltina, L. A., Petrova, S. F., et al. (2019). Glycyrrhizic Acid Derivatives as Dengue Virus Inhibitors. Bioorg. Med. Chem. Lett. 29, 126645. doi:10.1016/j.bmcl.2019.126645

Baltina, L. A., Zarubaev, V. V., Baltina, L. A., Orshanskaya, I. A., Fairushina, A. I., Kiselev, O. I., et al. (2015). Glycyrrhizic Acid Derivatives as Influenza A/H1N1 Virus Inhibitors. Bioorg. Med. Chem. Lett. 25, 1742-1746. doi:10.1016/ j.bmcl.2015.02.074

Bardou, O., Menou, A., François, C., Duitman, J. W., von der Thüsen, J. H., Borie, R., et al. (2016). Membrane-anchored Serine Protease Matriptase Is a Trigger of Pulmonary Fibrogenesis. Am. J. Respir. Crit. Care Med. 193, 847-860. doi:10.1164/rccm.201502-02990C

Battagello, D. S., Dragunas, G., Klein, M. O., Ayub, A. L. P., Velloso, F. J., and Correa, R. G. (2020). Unpuzzling COVID-19: Tissue-Related Signaling Pathways Associated with SARS-CoV-2 Infection and Transmission. Clin. Sci. (Lond) 134 (16), 2137-2160. doi:10.1042/CS20200904

Bhattacharjee, S., Bhattacharjee, A., Majumder, S., Majumdar, S. B., and Majumdar, S. (2012). Glycyrrhizic Acid Suppresses Cox-2-Mediated Anti-inflammatory Responses during Leishmania Donovani Infection. J. Antimicrob. Chemother. 67, 1905-1914. doi:10.1093/jac/dks159

Bonafé, G. A., Dos Santos, J. S., Ziegler, J. V., Umezawa, K., Ribeiro, M. L., Rocha, T., et al. (2019). Growth Inhibitory Effects of Dipotassium Glycyrrhizinate in Glioblastoma Cell Lines by Targeting MicroRNAs 
through the NF-Kb Signaling Pathway. Front Cel Neurosci 13, 216. doi:10.3389/fncel.2019.00216

Bordbar, N., Karimi, M. H., and Amirghofran, Z. (2012). The Effect of Glycyrrhizin on Maturation and T Cell Stimulating Activity of Dendritic Cells. Cell Immunol 280, 44-49. doi:10.1016/j.cellimm.2012.11.013

Cai, D., Mills, C., Yu, W., Yan, R., Aldrich, C. E., Saputelli, J. R., et al. (2012). Identification of Disubstituted Sulfonamide Compounds as Specific Inhibitors of Hepatitis B Virus Covalently Closed Circular DNA Formation. Antimicrob. Agents Chemother. 56, 4277-4288. doi:10.1128/ AAC.00473-12

Cantelli, B. A. M., Bitencourt, T. A., Komoto, T. T., Beleboni, R. O., Marins, M., and Fachin, A. L. (2017). Caffeic Acid and Licochalcone A Interfere with the Glyoxylate Cycle of Trichophyton Rubrum. Biomed. Pharmacother. 96, 1389-1394. doi:10.1016/j.biopha.2017.11.051

Catanzaro, M., Fagiani, F., Racchi, M., Corsini, E., Govoni, S., and Lanni, C. (2020). Immune Response in COVID-19: Addressing a Pharmacological challenge by Targeting Pathways Triggered by SARS-CoV-2. Signal. Transduct Target. Ther. 5 (1), 84. doi:10.1038/s41392-020-0191-1

Chen, H., and Du, Q. (2020a). Potential Natural Compounds for Preventing SARSCoV2 (2019-nCoV) Infection. Preprints 01, v3.

Chen, N., Zhou, M., Dong, X., Qu, J., Gong, F., Han, Y., et al. (2020b). Epidemiological and Clinical Characteristics of 99 Cases of 2019 Novel Coronavirus Pneumonia in Wuhan, China: a Descriptive Study. Lancet 395, 507-513. doi:10.1016/S0140-6736(20)30211-7

Chihong, W., Xiaoyuan, X., Haiying, L., Xiaohong, L., Fengqin, H., Yanyan, Y., et al. (2004). Analysis of the Chest X-ray Manifestations in SARS Patients Treated with Compound Glycyrrhizin Chin. pharm (01), 40-42.

Chrzanowski, J., Chrzanowska, A., and Graboń, W. (2021). Glycyrrhizin: An Old Weapon against a Novel Coronavirus. Phytother Res. 35 (2), 629-636. doi:10.1002/ptr.6852

Cinatl, J., Morgenstern, B., Bauer, G., Chandra, P., Rabenau, H., and Doerr, H. W. (2003). Glycyrrhizin, an Active Component of Liquorice Roots, and Replication of SARS-Associated Coronavirus. Lancet 361 (9374), 2045-2046. doi:10.1016/ s0140-6736(03)13615-x

Dai, X. H., Li, H. E., Lu, C. J., Wang, J. F., Dong, J., Wei, J. Y., et al. (2013). Liquiritigenin Prevents Staphylococcus Aureus-Mediated Lung Cell Injury via Inhibiting the Production of a-hemolysin. J. Asian Nat. Prod. Res. 15, 390-399. doi: $10.1080 / 10286020.2013 .771344$

Dao, T. T., Nguyen, P. H., Lee, H. S., Kim, E., Park, J., Lim, S. I., et al. (2011). Chalcones as Novel Influenza A (H1N1) Neuraminidase Inhibitors from Glycyrrhiza Inflata. Bioorg. Med. Chem. Lett. 21, 294-298. doi:10.1016/ j.bmcl.2010.11.016

Di Lorenzo, C., Ceschi, A., Kupferschmidt, H., Lüde, S., De Souza Nascimento, E., Dos Santos, A., et al. (2015). Adverse Effects of Plant Food Supplements and Botanical Preparations: a Systematic Review with Critical Evaluation of Causality. Br. J. Clin. Pharmacol. 79, 578-592. doi:10.1111/bcp.12519

Duan, E., Wang, D., Fang, L., Ma, J., Luo, J., Chen, H., et al. (2015). Suppression of Porcine Reproductive and Respiratory Syndrome Virus Proliferation by Glycyrrhizin. Antivir. Res 120, 122-125. doi:10.1016/j.antiviral.2015.06.001

Ei-Saber Batiha, G., Magdy Beshbishy, A., El-Mleeh, A., Abdel-Daim, M. M., and Prasad Devkota, H. (2020). . (Fabaceae). Biomolecules 10.Traditional Uses, Bioactive Chemical Constituents, and Pharmacological and Toxicological Activities of Glycyrrhiza Glabra L

Fang, L., Karakiulakis, G., and Roth, M. (2020). Are Patients with Hypertension and Diabetes Mellitus at Increased Risk for COVID-19 Infection? Lancet Respir. Med. 8, e21. doi:10.1016/S2213-2600(20)30116-8

Fatima, A., Gupta, V. K., Luqman, S., Negi, A. S., Kumar, J. K., Shanker, K., et al. (2009). Antifungal Activity of Glycyrrhiza Glabra Extracts and its Active Constituent Glabridin. Phytother Res. 23 (8), 1190-1193. doi:10.1002/ptr.2726

Feng Yeh, C., Wang, K. C., Chiang, L. C., Shieh, D. E., Yen, M. H., and San Chang, J. (2013). Water Extract of Licorice Had Anti-viral Activity against Human Respiratory Syncytial Virus in Human Respiratory Tract Cell Lines. J. Ethnopharmacol 148, 466-473. doi:10.1016/j.jep.2013.04.040

Fiore, C., Eisenhut, M., Ragazzi, E., Zanchin, G., and Armanini, D. (2005). A History of the Therapeutic Use of Liquorice in Europe. J. Ethnopharmacol 99, 317-324. doi:10.1016/j.jep.2005.04.015

Fontes, L. B., Dos Santos Dias, D., de Carvalho, L. S., Mesquita, H. L., da Silva Reis, L., Dias, A. T., et al. (2014). Immunomodulatory Effects of Licochalcone A on
Experimental Autoimmune Encephalomyelitis. J. Pharm. Pharmacol. 66, 886-894. doi:10.1111/jphp.12212

Fu, L., Wang, B., Yuan, T., Chen, X., Ao, Y., Fitzpatrick, T., et al. (2020). Clinical Characteristics of Coronavirus Disease 2019 (COVID-19) in China: A Systematic Review and Meta-Analysis. J. Infect. 80 (6), 656-665. doi:10.1016/j.jinf.2020.03.041

Fu, X., Wang, Z., Li, L., Dong, S., Li, Z., Jiang, Z., et al. (2016). Novel Chemical Ligands to Ebola Virus and Marburg Virus Nucleoproteins Identified by Combining Affinity Mass Spectrometry and Metabolomics Approaches. Sci. Rep. 6, 29680. doi:10.1038/srep29680

Fu, Y., Zhou, E., Wei, Z., Liang, D., Wang, W., Wang, T., et al. (2014a). Glycyrrhizin Inhibits the Inflammatory Response in Mouse Mammary Epithelial Cells and a Mouse Mastitis Model. FEBS J. 281, 2543-2557. doi:10.1111/febs.12801

Fu, Y., Zhou, E., Wei, Z., Song, X., Liu, Z., Wang, T., et al. (2014b). Glycyrrhizin Inhibits Lipopolysaccharide-Induced Inflammatory Response by Reducing TLR4 Recruitment into Lipid Rafts in RAW264.7 Cells. Biochim. Biophys. Acta 1840, 1755-1764. doi:10.1016/j.bbagen.2014.01.024

Fukuchi, K., Okudaira, N., Adachi, K., Odai-Ide, R., Watanabe, S., Ohno, H., et al. (2016). Antiviral and Antitumor Activity of Licorice Root Extracts. In Vivo 30, 777-785. doi:10.21873/invivo.10994

Gao, L., Tang, H., He, H., Liu, J., Mao, J., Ji, H., et al. (2015). Glycyrrhizic Acid Alleviates Bleomycin-Induced Pulmonary Fibrosis in Rats. Front. Pharmacol. 6, 215. doi:10.3389/fphar.2015.00215

Gaur, R., Gupta, V. K., Singh, P., Pal, A., Darokar, M. P., and Bhakuni, R. S. (2016). Drug Resistance Reversal Potential of Isoliquiritigenin and Liquiritigenin Isolated from Glycyrrhiza Glabra against Methicillin-Resistant Staphylococcus aureus (MRSA). Phytother Res. 30, 1708-1715. doi:10.1002/ ptr.5677

Gaur, R., Yadav, K. S., Verma, R. K., Yadav, N. P., and Bhakuni, R. S. (2014). In Vivo anti-diabetic Activity of Derivatives of Isoliquiritigenin and Liquiritigenin. Phytomedicine 21, 415-422. doi:10.1016/j.phymed.2013.10.015

Gong, G., Yuan, L. B., Hu, L., Wu, W., Yin, L., Hou, J. L., et al. (2012). Glycyrrhizin Attenuates Rat Ischemic Spinal Cord Injury by Suppressing Inflammatory Cytokines and HMGB1. Acta Pharmacol. Sin 33, 11-18. doi:10.1038/ aps.2011.151

Guan, Y., Li, F. F., Hong, L., Yan, X. F., Tan, G. L., He, J. S., et al. (2012). Protective Effects of Liquiritin Apioside on Cigarette Smoke-Induced Lung Epithelial Cell Injury. Fundam. Clin. Pharmacol. 26, 473-483. doi:10.1111/j.14728206.2011.00956.x

Guo, A., He, D., Xu, H. B., Geng, C. A., and Zhao, J. (2015). Promotion of Regulatory T Cell Induction by Immunomodulatory Herbal Medicine Licorice and its Two Constituents. Sci. Rep. 5, 14046. doi:10.1038/srep14046

Guo, Y. R., Cao, Q. D., Hong, Z. S., Tan, Y. Y., Chen, S. D., Jin, H. J., et al. (2020). The Origin, Transmission and Clinical Therapies on Coronavirus Disease 2019 (COVID-19) Outbreak - an Update on the Status. Mil. Med. Res. 7 (1), 11. doi:10.1186/s40779-020-00240-0

Hamming, I., Timens, W., Bulthuis, M. L., Lely, A. T., Navis, G., and van Goor, H. (2004). Tissue Distribution of ACE2 Protein, the Functional Receptor for SARS Coronavirus. A First Step in Understanding SARS Pathogenesis. J. Pathol. 203, 631-637. doi:10.1002/path.1570

Han, S., Sun, L., He, F., and Che, H. (2017). Anti-allergic Activity of Glycyrrhizic Acid on IgE-Mediated Allergic Reaction by Regulation of Allergy-Related Immune Cells. Sci. Rep. 7, 7222. doi:10.1038/s41598-017-07833-1

Hao, H., Hui, W., Liu, P., Lv, Q., Zeng, X., Jiang, H., et al. (2013). Effect of Licochalcone A on Growth and Properties of Streptococcus Suis. PloS one 8, e67728. doi:10.1371/journal.pone.0067728

Hardy, M. E., Hendricks, J. M., Paulson, J. M., and Faunce, N. R. (2012). $18 \beta$ glycyrrhetinic Acid Inhibits Rotavirus Replication in Culture. Virol. J. 9, 96. doi:10.1186/1743-422x-9-96

Hendricks, J. M., Hoffman, C., Pascual, D. W., and Hardy, M. E. (2012). 18ßGlycyrrhetinic Acid Delivered Orally Induces Isolated Lymphoid Follicle Maturation at the Intestinal Mucosa and Attenuates Rotavirus Shedding. PloS one 7, e49491. doi:10.1371/journal.pone.0049491

Hong, L., Tieji, K., Yan, L., Jufang, H., and Mei, D. (2004). Analysis of Bacterial and Fungal Infections in Patients with SARS. Chin. J. Clin. Lab. Sci. 03, 171.

Hongrong, L., Liping, C., Cong, W., and Zhenhua, J. (2020). Theoretical Research Basis and Clinical Efficacy of Lianhua Qingwen in Treating Novel Coronavious Pneumonica. World Chin. Med. 15, 332-336. 
Hsieh, W. L., Lin, Y. K., Tsai, C. N., Wang, T. M., Chen, T. Y., and Pang, J. H. (2012). Indirubin, an Acting Component of Indigo Naturalis, Inhibits EGFR Activation and EGF-Induced CDC25B Gene Expression in Epidermal Keratinocytes. J. Dermatol. Sci. 67, 140-146. doi:10.1016/j.jdermsci.2012.05.008

Hu, K., Guan, W. J., Bi, Y., Zhang, W., Li, L., Zhang, B., et al. (2020). Efficacy and Safety of Lianhuaqingwen Capsules, a Repurposed Chinese Herb, in Patients with Coronavirus Disease 2019: A Multicenter, Prospective, Randomized Controlled Trial. Netherlands: Phytomedicine 85, 153242.

Huang, W., Chen, X., Li, Q., Li, P., Zhao, G., Xu, M., et al. (2012). Inhibition of Intercellular Adhesion in Herpex Simplex Virus Infection by Glycyrrhizin. Cell Biochem Biophys 62, 137-140. doi:10.1007/s12013-011-9271-8

Indhu, B. S., and Shajahan, M. A. (2018). Pharmacognostic Evaluation of Glycyrrhiza Glabra Linn (Yashtimadhu) from Raw Drug Markets of Kerala. Int. J. Adv. Res. 10, 710-719.

Ishida, T., Miki, I., Tanahashi, T., Yagi, S., Kondo, Y., Inoue, J., et al. (2013). Effect of 18 $\beta$-Glycyrrhetinic Acid and Hydroxypropyl $\gamma$ cyclodextrin Complex on Indomethacin-Induced Small Intestinal Injury in Mice. Eur. J. Pharmacol. 714, 125-131. doi:10.1016/j.ejphar.2013.06.007

Jia, T., Qiao, J., Guan, D., and Chen, T. (2017). Anti-Inflammatory Effects of Licochalcone A on IL-1 $\beta$-Stimulated Human Osteoarthritis Chondrocytes. Inflammation 40, 1894-1902. doi:10.1007/s10753-017-0630-5

Jose, R. J., and Manuel, A. (2020). COVID-19 Cytokine Storm: the Interplay between Inflammation and Coagulation. Lancet Respir. Med. 8 (6), e46-e47. doi:10.1016/S2213-2600(20)30216-2

Kaitao, Y., Mingyu, L., Xin, L., Jihan, H., and Hongbin, C. (2020). Retrospective Clinical Analysis on Treatment of Coronavirus Disease 2019 with Traditional Chinese Medicine Lianhua Qingwen. Zhongguo Shi Yan Fang Ji Xue Za Zhi 26 (11), 8-12.

Kim, J. M., Kim, K. S., Lee, Y. W., Cho, C. K., Yoo, H. S., Bang, J. Y., et al. (2011a). Anti-angiogenic Effects of Water Extract of a Formula Consisting of Pulsatilla Koreana, Panax Ginseng and Glycyrrhiza Uralensis. Zhong Xi Yi Jie He Xue Bao 9, 1005-1013. doi:10.3736/jcim20110912

Kim, S. H., Hong, J. H., Yang, W. K., Geum, J. H., Kim, H. R., Choi, S. Y., et al. (2020). Herbal Combinational Medication of Glycyrrhiza Glabra, Agastache Rugosa Containing Glycyrrhizic Acid, Tilianin Inhibits Neutrophilic Lung Inflammation by Affecting CXCL2, Interleukin-17/STAT3 Signal Pathways in a Murine Model of COPD. Nutrients 12, 926. doi:10.3390/nu12040926

Kim, S. J., Kim, C. G., Yun, S. R., Kim, J. K., and Jun, J. G. (2014). Synthesis of Licochalcone Analogues with Increased Anti-inflammatory Activity. Bioorg. Med. Chem. Lett. 24, 181-185. doi:10.1016/j.bmcl.2013.11.044

Kim, S. W., Jin, Y., Shin, J. H., Kim, I. D., Lee, H. K., Park, S., et al. (2012). Glycyrrhizic Acid Affords Robust Neuroprotection in the Postischemic Brain via Anti-inflammatory Effect by Inhibiting HMGB1 Phosphorylation and Secretion. Neurobiol. Dis. 46, 147-156. doi:10.1016/j.nbd.2011.12.056

Kim, Y. W., Kim, Y. M., Yang, Y. M., Kay, H. Y., Kim, W. D., Lee, J. W., et al. (2011b). Inhibition of LXRa-dependent Steatosis and Oxidative Injury by Liquiritigenin, a Licorice Flavonoid, as Mediated with Nrf2 Activation. Antioxid. Redox Signal. 14, 733-745. doi:10.1089/ars.2010.3260

Kuete, V., Ngameni, B., Mbaveng, A. T., Ngadjui, B., Meyer, J. J., and Lall, N. (2010). Evaluation of Flavonoids from Dorstenia Barteri for Their Antimycobacterial, Antigonorrheal and Anti-reverse Transcriptase Activities. Acta Trop. 116, 100-104. doi:10.1016/j.actatropica.2010.06.005

Lan, J., Ge, J., Yu, J., Shan, S., Zhou, H., Fan, S., et al. (2020). Structure of the SARSCoV-2 Spike Receptor-Binding Domain Bound to the ACE2 Receptor. Nature 581, 215-220. doi:10.1038/s41586-020-2180-5

Lee, H. E., Yang, G., Han, S. H., Lee, J. H., An, T. J., Jang, J. K., et al. (2018). Antiobesity Potential of Glycyrrhiza Uralensis and Licochalcone A through Induction of Adipocyte browning. Biochem. Biophys. Res. Commun. 503, 2117-2123. doi:10.1016/j.bbrc.2018.07.168

Lee, J. S., Bukhari, S. N., and Fauzi, N. M. (2015a). Effects of Chalcone Derivatives on Players of the Immune System. Drug Des. Devel Ther. 9, 4761-4778. doi:10.2147/DDDT.S86242

Lee, M., Son, M., Ryu, E., Shin, Y. S., Kim, J. G., Kang, B. W., et al. (2015b). Quercetin-induced Apoptosis Prevents EBV Infection. Oncotarget 6, 12603-12624. doi:10.18632/oncotarget.3687

Lee, S., Lee, H. H., Shin, Y. S., Kang, H., and Cho, H. (2017). The Anti-HSV-1 Effect of Quercetin Is Dependent on the Suppression of TLR-3 in Raw 264.7 Cells. Arch. Pharm. Res. 40, 623-630. doi:10.1007/s12272-017-0898-x
Leung, J. M., Yang, C. X., Tam, A., Shaipanich, T., Hackett, T. L., Singhera, G. K., et al. (2020). ACE-2 Expression in the Small Airway Epithelia of Smokers and COPD Patients: Implications for COVID-19. Eur. Respir. J. 55, 00688-02020. doi:10.1183/13993003.00688-2020

Li, G., Nikolic, D., and van Breemen, R. B. (2016). Identification and Chemical Standardization of Licorice Raw Materials and Dietary Supplements Using UHPLC-MS/MS. J. Agric. Food Chem. 64, 8062-8070. doi:10.1021/ acs.jafc.6b02954

Li, G., Li, X., and Li, Q. (2017). Effect of Glycyrrhizin on Bleomycin-Induced Pulmonary Fibrosis. Chin. J. Pathophysiol. 33, 528-533.

Li, S., Wang, J., Zhang, B., Li, X., and Liu, Y. (2019). Diabetes Mellitus and Causespecific Mortality: A Population-Based Study. Diabetes Metab. J. 43, 319-341. doi:10.4093/dmj.2018.0060

Li, S., Zhu, J. H., Cao, L. P., Sun, Q., Liu, H. D., Li, W. D., et al. (2014). Growth Inhibitory In Vitro Effects of Glycyrrhizic Acid in U251 Glioblastoma Cell Line. Neurol. Sci. 35, 1115-1120. doi:10.1007/s10072-014-1661-4

Li, Y., Sun, F., Jing, Z., Wang, X., Hua, X., and Wan, L. (2017). Glycyrrhizic Acid Exerts Anti-inflammatory Effect to Improve Cerebral Vasospasm Secondary to Subarachnoid Hemorrhage in a Rat Model. Neurol. Res. 39, 727-732. doi:10.1080/01616412.2017.1316903

Lin, S. C., Ho, C. T., Chuo, W. H., Li, S., Wang, T. T., and Lin, C. C. (2017). Effective Inhibition of MERS-CoV Infection by Resveratrol. BMC Infect. Dis. 17, 144. doi:10.1186/s12879-017-2253-8

Ling, C., Taichang, Z., and Mei, Z. (2004). Observation of the Eiffeacy of Eompound Glycyrrhizin in Treatment of SARS. Chin. J. New Drugs (09), 842-845.

Liu, Z. J., Zhong, J., Zhang, M., Chen, Z. H., Wang, J. Y., Chen, H. Y., et al. (2019). The Alexipharmic Mechanisms of Five Licorice Ingredients Involved in CYP450 and Nrf2 Pathways in Paraquat-Induced Mice Acute Lung Injury. Oxid Med. Cel Longev 2019, 7283104. doi:10.1155/2019/7283104

Long, D. R., Mead, J., Hendricks, J. M., Hardy, M. E., and Voyich, J. M. (2013). 18ßGlycyrrhetinic Acid Inhibits Methicillin-Resistant Staphylococcus aureus Survival and Attenuates Virulence Gene Expression. Antimicrob. Agents Chemother. 57, 241-247. doi:10.1128/aac.01023-12

Luo, L., Jin, Y., and Kim, I. D. (2013). Glycyrrhizin Attenuates Kainic Acid-Induced Neuronal Cell Death in the Mouse Hippocampus. Exp. Neurobiol. 22, 107-115.

Luo, C. H., Ma, L. L., Liu, H. M., Liao, W., Xu, R. C., Ci, Z. M., et al. (2020). Research Progress on Main Symptoms of Novel Coronavirus Pneumonia Improved by Traditional Chinese Medicine. Front. Pharmacol. 11, 556885. doi:10.3389/ fphar.2020.556885

Ma, C., Ma, Z., Liao, X. L., Liu, J., Fu, Q., and Ma, S. (2013). Immunoregulatory Effects of Glycyrrhizic Acid Exerts Anti-asthmatic Effects via Modulation of Th1/Th2 Cytokines and Enhancement of CD4(+)CD25(+)Foxp3+ Regulatory $\mathrm{T}$ Cells in Ovalbumin-Sensitized Mice. J. Ethnopharmacol 148, 755-762. doi:10.1016/j.jep.2013.04.021

Ma, Q., Liu, C., and Du, H. (2020). Virtual Screening of Small Molecular Inhibitors of SARS-CoV2 3CL Hydrolase Based on High-Throughput Molecular Docking and Prediction of Chinese Materia Medica and its Compound against COVID19. Chin. Tradit. Herbal Drugs 51, 1397-1405.

Ma, L. L., Liu, H. M., Liu, X. M., Yuan, X. Y., Xu, C., and Wang, F. (2021). Screening S Protein - ACE 2 Blockers from Natural Products: Strategies and Advances in the Discovery of Potential Inhibitors of COVID-19.. Eur. J. Med. Chem. 226, 113857.

Matsumoto, Y., Matsuura, T., Aoyagi, H., Matsuda, M., Hmwe, S. S., Date, T., et al. (2013). Antiviral Activity of Glycyrrhizin against Hepatitis C Virus In Vitro. PloS one 8, e68992. doi:10.1371/journal.pone.0068992

Matsuyama, T., Kubli, S. P., Yoshinaga, S. K., Pfeffer, K., and Mak, T. W. (2020). An Aberrant STAT Pathway Is central to COVID-19. Cell Death Differ 27 (12), 3209-3225. doi:10.1038/s41418-020-00633-7

Mbaveng, A. T., Ngameni, B., Kuete, V., Simo, I. K., Ambassa, P., Roy, R., et al. (2008). Antimicrobial Activity of the Crude Extracts and Five Flavonoids from the Twigs of Dorstenia Barteri (Moraceae). J. Ethnopharmacol 116, 483-489. doi:10.1016/j.jep.2007.12.017

McDonald, H. I., Nitsch, D., Millett, E. R., Sinclair, A., and Thomas, S. L. (2014). New Estimates of the burden of Acute Community-Acquired Infections Among Older People with Diabetes Mellitus: a Retrospective Cohort Study Using Linked Electronic Health Records. Diabet Med. 31, 606-614. doi:10.1111/ dme.12384 
Mehta, P., McAuley, D. F., Brown, M., Sanchez, E., Tattersall, R. S., and Manson, J. J. (2020). COVID-19: Consider Cytokine Storm Syndromes and Immunosuppression. Lancet 395, 1033-1034. doi:10.1016/S0140-6736(20) 30628-0

Messier, C., and Grenier, D. (2011). Effect of Licorice Compounds Licochalcone A, Glabridin and Glycyrrhizic Acid on Growth and Virulence Properties of Candida Albicans. Mycoses 54, e801-6. doi:10.1111/j.14390507.2011.02028.x

Michaelis, M., Geiler, J., Naczk, P., Sithisarn, P., Leutz, A., Doerr, H. W., et al. (2011). Glycyrrhizin Exerts Antioxidative Effects in H5N1 Influenza A Virus-Infected Cells and Inhibits Virus Replication and Proinflammatory Gene Expression. PloS one 6, e19705. doi:10.1371/ journal.pone.0019705

Michaelis, M., Geiler, J., Naczk, P., Sithisarn, P., Ogbomo, H., Altenbrandt, B., et al. (2010). Glycyrrhizin Inhibits Highly Pathogenic H5N1 Influenza A VirusInduced Pro-inflammatory Cytokine and Chemokine Expression in Human Macrophages. Med. Microbiol. Immunol. 199, 291-297. doi:10.1007/s00430010-0155-0

Min, J., Hao, M. Z., Hu, J., and Yuan, B. (2009). Effect of Licorice Polysaccharide on Cellular Immunity in Mice. J. HUBEI Pol. Inst. 12, 106-108.

Mitra Mazumder, P., Pattnayak, S., Parvani, H., Sasmal, D., and Rathinavelusamy, P. (2012). Evaluation of Immunomodulatory Activity of Glycyrhiza Glabra L Roots in Combination with Zing. Asian Pac. J. Trop. Biomed. 2, S15-S20. doi:10.1016/s2221-1691(12)60122-1

Moisy, D., Avilov, S. V., Jacob, Y., Laoide, B. M., Ge, X., Baudin, F., et al. (2012). HMGB1 Protein Binds to Influenza Virus Nucleoprotein and Promotes Viral Replication. J. Virol. 86, 9122-9133. doi:10.1128/JVI.00789-12

Montoro, P., Maldini, M., Russo, M., Postorino, S., Piacente, S., and Pizza, C. (2011). Metabolic Profiling of Roots of Liquorice (Glycyrrhiza Glabra) from Different Geographical Areas by ESI/MS/MS and Determination of Major Metabolites by LC-ESI/MS and LC-ESI/MS/MS. J. Pharm. Biomed. Anal. 54, 535-544. doi:10.1016/j.jpba.2010.10.004

Murck, H. (2020). Symptomatic Protective Action of Glycyrrhizin (Licorice) in COVID-19 Infection? Front. Immunol. 11, 1239. doi:10.3389/ fimmu.2020.01239

Namdar Ahmadabad, H., Shafiei, R., Hatam, G. R., Zolfaghari Emameh, R., and Aspatwar, A. (2020). Cytokine Profile and Nitric Oxide Levels in Peritoneal Macrophages of BALB/c Mice Exposed to the Fucose-Mannose Ligand of Leishmania Infantum Combined with Glycyrrhizin. Parasit Vectors 13, 363. doi:10.1186/s13071-020-04243-7

Nomura, T., Fukushi, M., Oda, K., Higashiura, A., Irie, T., and Sakaguchi, T. (2019). Effects of Traditional Kampo Drugs and Their Constituent Crude Drugs on Influenza Virus Replication In Vitro: Suppression of Viral Protein Synthesis by Glycyrrhizae Radix. Evid. Based Complement. Alternat Med. 2019, 3230906. doi:10.1155/2019/3230906

Oyama, K., Kawada-Matsuo, M., Oogai, Y., Hayashi, T., Nakamura, N., and Komatsuzawa, H. (2016). Antibacterial Effects of Glycyrrhetinic Acid and its Derivatives on Staphylococcus aureus. PloS one 11, e0165831. doi:10.1371/journal.pone.0165831

Oztanir, M. N., Ciftci, O., Cetin, A., Durak, M. A., Basak, N., and Akyuva, Y. (2014). The Beneficial Effects of $18 \beta$-Glycyrrhetinic Acid Following Oxidative and Neuronal Damage in Brain Tissue Caused by Global Cerebral Ischemia/ reperfusion in a C57BL/J6 Mouse Model. Neurol. Sci. 35, 1221-1228. doi:10.1007/s10072-014-1685-9

Öztürk, M., Altay, V., Hakeem, K. R., and Akçiçek, E. (2018). "Economic Importance," in Liquorice. SpringerBriefs in Plant Science (Cham: Springer), 73-126. doi:10.1007/978-3-319-74240-3_8

Park, H. G., Bak, E. J., Woo, G. H., Kim, J. M., Quan, Z., Kim, J. M., et al. (2012). Licochalcone E Has an Antidiabetic Effect. J. Nutr. Biochem. 23, 759-767. doi:10.1016/j.jnutbio.2011.03.021

Pearson-Stuttard, J., Blundell, S., Harris, T., Cook, D. G., and Critchley, J. (2016). Diabetes and Infection: Assessing the Association with Glycaemic Control in Population-Based Studies. Lancet Diabetes Endocrinol. 4, 148-158. doi:10.1016/ S2213-8587(15)00379-4

Poduri, R., Joshi, G., and Jagadeesh, G. (2020). Drugs Targeting Various Stages of the SARS-CoV-2 Life Cycle: Exploring Promising Drugs for the Treatment of Covid-19. Cell Signal 74, 109721. doi:10.1016/j.cellsig.2020.109721
Powers, C. N., and Setzer, W. N. (2016). An In-Silico Investigation of Phytochemicals as Antiviral Agents against Dengue Fever. Comb. Chem. High Throughput Screen. 19, 516-536. doi:10.2174/1386207319666160506123715

Qiao, Z., Xue, L. L., Mei, H. L., Jian, L., and Qing, W. Z. (2020). The Distribution of Angiotensin-Converting Enzyme 2 (ACE2) and the Intervention Strategies Targeting the Binding Process of SARS-CoV2 and ACE2. Chin. Pharm. J. 55, 665-670.

Rajasekaran, S., Rajaguru, P., and Sudhakar Gandhi, P. S. (2015). MicroRNAs as Potential Targets for Progressive Pulmonary Fibrosis. Front. Pharmacol. 6, 254. doi:10.3389/fphar.2015.00254

Rehman, M. F. U., Akhter, S., Batool, A. I., Selamoglu, Z., Sevindik, M., Eman, R., et al. (2021). Effectiveness of Natural Antioxidants against SARS-CoV-2? Insights from the In-Silico World. Antibiotics (Basel) 10 (8), 1011. doi:10.3390/antibiotics10081011

Rodino, S., Butu, A., and Butu, M. (2015). Comparative Studies on Antibacterial Activity of Licorice, Elderberry and Dandelion. Dig. J. Nanomater. Biostruct 10, 947-955.

Sakai-Sugino, K., Uematsu, J., Kamada, M., Taniguchi, H., Suzuki, S., Yoshimi, Y., et al. (2017). Glycyrrhizin Inhibits Human Parainfluenza Virus Type 2 Replication by the Inhibition of Genome RNA, mRNA and Protein Syntheses. Drug Discov. Ther. 11, 246-252. doi:10.5582/ddt.2017.01048

Schmidt, S., Heymann, K., and Melzig, M. F. (2016). Glycyrrhizic Acid Decreases Gentamicin-Resistance in Vancomycin-Resistant Enterococci. Planta. Med. 82 (18), 1540-1545.

Selyutina, O. Y., Apanasenko, I. E., Kim, A. V., Shelepova, E. A., Khalikov, S. S., and Polyakov, N. E. (2016a). Spectroscopic and Molecular Dynamics Characterization of Glycyrrhizin Membrane-Modifying Activity. Colloids Surf. B Biointerfaces 147, 459-466. doi:10.1016/j.colsurfb.2016.08.037

Selyutina, O. Y., and Polyakov, N. E. (2019). Glycyrrhizic Acid as a Multifunctional Drug Carrier - from Physicochemical Properties to Biomedical Applications: A Modern Insight on the Ancient Drug. Int. J. Pharm. 559, 271-279. doi:10.1016/ j.ijpharm.2019.01.047

Selyutina, O. Y., Polyakov, N. E., Korneev, D. V., and Zaitsev, B. N. (2016b). Influence of Glycyrrhizin on Permeability and Elasticity of Cell Membrane: Perspectives for Drugs Delivery. Drug Deliv. 23 (3), 858-865. doi:10.3109/ 10717544.2014.919544

Shah, V. K., Firmal, P., Alam, A., Ganguly, D., and Chattopadhyay, S. (2020). Overview of Immune Response during SARS-CoV-2 Infection: Lessons from the Past. Front. Immunol. 11, 1949. doi:10.3389/fimmu.2020.01949

Shikov, A. N., Narkevich, I. A., Flisyuk, E. V., Luzhanin, V. G., and Pozharitskaya, O. N. (2021). Medicinal Plants from the 14th Edition of the Russian Pharmacopoeia, Recent Updates. J. Ethnopharmacol 268, 113685. doi:10.1016/j.jep.2020.113685

Shubin, F., Guang, X., and Yuan, G. (2018). Inhibitory Effect and Mechanism of Licochalcone A on NLRP3 Inflammasome. Acta Pharmaceutica Sinica 53, 2050-2056.

Song, W., Si, L., Ji, S., Wang, H., Fang, X. M., Yu, L. Y., et al. (2014). Uralsaponins M-Y, Antiviral Triterpenoid Saponins from the Roots of Glycyrrhiza Uralensis. J. Nat. Prod. 77, 1632-1643. doi:10.1021/np500253m

Soufy, H., Yassein, S., Ahmed, A. R., Khodier, M. H., Kutkat, M. A., Nasr, S. M., et al. (2012). Antiviral and Immune Stimulant Activities of Glycyrrhizin against Duck Hepatitis Virus. Afr. J. Tradit Complement. Altern. Med. 9, 389-395. doi:10.4314/ajtcam.v9i3.14

Su, X., Li, T., Liu, Z., Huang, Q., Liao, K., Ren, R., et al. (2018). Licochalcone A Activates Keap1-Nrf2 Signaling to Suppress Arthritis via Phosphorylation of P62 at Serine 349. Free Radic. Biol. Med. 115, 471-483. doi:10.1016/ j.freeradbiomed.2017.12.004

Sun, X., Zeng, H., Wang, Q., Yu, Q., Wu, J., Feng, Y., et al. (2018). Glycyrrhizin Ameliorates Inflammatory Pain by Inhibiting Microglial Activation-Mediated Inflammatory Response via Blockage of the HMGB1-TLR4-NF-kB Pathway. Exp. Cell Res. 369 (1), 112-119. doi:10.1016/j.yexcr.2018.05.012

Sun, Z. G., Zhao, T. T., Lu, N., Yang, Y. A., and Zhu, H. L. (2019). Research Progress of Glycyrrhizic Acid on Antiviral Activity. Mini Rev. Med. Chem. 19, 826-832. doi:10.2174/1389557519666190119111125

Tan, C., Wu, Y., and Lin, R. (2014). Mechanism of Glabridin on the Protection of Human Aorta Vascular Endothelial Cells Induced by Ox-LDL. Acta Chin. Med. Pharm. 42, 16-19. 
Tang, T., Bidon, M., Jaimes, J. A., Whittaker, G. R., and Daniel, S. (2020). Coronavirus Membrane Fusion Mechanism Offers a Potential Target for Antiviral Development. Antivir. Res 178, 104792. doi:10.1016/ j.antiviral.2020.104792

Tomar, P. P. S., Krugliak, M., and Arkin, I. T. (2021). Identification of SARS-CoV-2 E Channel Blockers from a Repurposed Drug Library. Pharmaceuticals 2314 (7), 604. doi:10.3390/ph14070604

Tsao, S. M., and Yin, M. C. (2015). Antioxidative and Antiinflammatory Activities of Asiatic Acid, Glycyrrhizic Acid, and Oleanolic Acid in Human Bronchial Epithelial Cells. J. Agric. Food Chem. 63, 3196-3204. doi:10.1021/ acs.jafc.5b00102

Tsukahara, M., Nishino, T., Furuhashi, I., Inoue, H., Sato, T., and Matsumoto, H. (2005). Synthesis and Inhibitory Effect of Novel Glycyrrhetinic Acid Derivatives on IL-1.BETA.-Induced Prostaglandin E2 Production in Normal Human Dermal Fibroblasts. Chem. Pharm. Bull. 53, 1103-1110. doi:10.1248/ cpb.53.1103

Tsukiyama, R., Katsura, H., Tokuriki, N., and Kobayashi, M. (2002). Antibacterial Activity of Licochalcone A against Spore-Forming Bacteria. Antimicrob. Agents Chemother. 46, 1226-1230. doi:10.1128/aac.46.5.1226-1230.2002

Vanderbeke, L., Spriet, I., Breynaert, C., Rijnders, B. J. A., Verweij, P. E., and Wauters, J. (2018). Invasive Pulmonary Aspergillosis Complicating Severe Influenza: Epidemiology, Diagnosis and Treatment. Curr. Opin. Infect. Dis. 31 (6), 471-480. doi:10.1097/QCO.0000000000000504

Varga, Z., Flammer, A. J., Steiger, P., Haberecker, M., Andermatt, R., Zinkernagel, A. S., et al. (2020). Endothelial Cell Infection and Endotheliitis in COVID-19. Lancet 395, 1417-1418. doi:10.1016/S0140-6736(20)30937-5

Wang, B., Lian, Y. J., Dong, X., Peng, W., Liu, L. L., Su, W. J., et al. (2018a). Glycyrrhizic Acid Ameliorates the Kynurenine Pathway in Association with its Antidepressant Effect. Behav. Brain Res. 353, 250-257. doi:10.1016/ j.bbr.2018.01.024

Wang, B. K., Mao, Y. L., Gong, L., Xu, X., Jiang, S. Q., Wang, Y. B., et al. (2018b). Glycyrrhizic Acid Activates Chicken Macrophages and Enhances Their Salmonella-Killing Capacity In Vitro. J. Zhejiang Univ. Sci. B 19, 785-795. doi:10.1631/jzus.B1700506

Wang, C., Chen, L., Xu, C., Shi, J., Chen, S., Tan, M., et al. (2020a). A Comprehensive Review for Phytochemical, Pharmacological, and Biosynthesis Studies on Glycyrrhiza Spp. Am. J. Chin. Med. 48, 17-45. doi:10.1142/S0192415X20500020

Wang, C., Shi, D., Zhang, F., Yu, X., Lin, G., and Zhou, Z. (2020b). Characterization of Binding Interaction between Magnesium Isoglycyrrhizinate and Human Serum Albumin. Spectrochim Acta A. Mol. Biomol. Spectrosc. 234, 118245. doi:10.1016/j.saa.2020.118245

Wang, D., Liang, J., Zhang, J., Wang, Y., and Chai, X. (2020c). Natural Chalcones in Chinese Materia Medica: Licorice. Egypt: Evid Based Complement Alternat Med. 16, 3821248.

Wang, H., Shan, H., and Lü, H. (2020d). Preparative Separation of Liquiritigenin and Glycyrrhetic Acid from Glycyrrhiza Uralensis Fisch Using Hydrolytic Extraction Combined with High-Speed Countercurrent Chromatography. Biomed. Chromatogr. 34, e4788. doi:10.1002/bmc.4788

Wang, J., Chen, X., Wang, W., Zhang, Y., Yang, Z., Jin, Y., et al. (2013a). Glycyrrhizic Acid as the Antiviral Component of Glycyrrhiza Uralensis Fisch. Against Coxsackievirus A16 and Enterovirus 71 of Hand Foot and Mouth Disease. J. Ethnopharmacol 147, 114-121. doi:10.1016/ j.jep.2013.02.017

Wang, J., Zhou, B., Hu, X., Dong, S., Hong, M., Wang, J., et al. (2021). Deciphering the Formulation Secret Underlying Chinese Huo-Clearing Herbal Drink. Front. Pharmacol. 12, 654699. doi:10.3389/fphar.2021.654699

Wang, L.-q., He, Y., Wan, H.-f., Zhou, H.-f., Yang, J.-h., and Wan, H.-t. (2017). Protective Mechanisms of Hypaconitine and Glycyrrhetinic Acid Compatibility in Oxygen and Glucose Deprivation Injury. J. Zhejiang Univ. Sci. B 18, 586-596. doi:10.1631/jzus.b1600270

Wang, R., Liu, Y., and Chen, J. (2019). Antitumor Mechanism of Glycyrrhizin and Glycyrrhizin and Their Application as Drug Delivery Carriers. Chin. Tradit. Herbal Drugs 50, 5876-5886.

Wang, Z., Cao, Y., Paudel, S., Yoon, G., and Cheon, S. H. (2013b). Concise Synthesis of Licochalcone C and its Regioisomer, Licochalcone H. Arch. Pharm. Res. 36, 1432-1436. doi:10.1007/s12272-013-0222-3
Wang, L., Yang, R., and Yuan, B. (2015). The Antiviral and Antimicrobial Activities of Licorice, a Widely-Used Chinese Herb. Acta Pharm. Sin. B 5 (4), 310-315.

Wen, Y., Liu, Y., Tang, T., Lv, L., Liu, H., Ma, K., et al. (2016). NLRP3 Inflammasome Activation Is Involved in Ang II-Induced Kidney Damage via Mitochondrial Dysfunction. Oncotarget 7, 54290-54302. doi:10.18632/ oncotarget.11091

Wu, C., Chen, X., Cai, Y., Xia, J., Zhou, X., Xu, S., et al. (2020). Risk Factors Associated with Acute Respiratory Distress Syndrome and Death in Patients with Coronavirus Disease 2019 Pneumonia in Wuhan, China. JAMA Intern. Med. 180, 934-943. doi:10.1001/jamainternmed.2020.0994

Wu, F., Jin, Z., and Jin, J. (2013). Hypoglycemic Effects of Glabridin, a Polyphenolic Flavonoid from Licorice, in an Animal Model of Diabetes Mellitus. Mol. Med. Rep. 7, 1278-1282. doi:10.3892/mmr.2013.1330

Wu, X., Wang, W., Chen, Y., Liu, X., Wang, J., Qin, X., et al. (2018). Glycyrrhizin Suppresses the Growth of Human NSCLC Cell Line HCC827 by Downregulating HMGB1 Level. Biomed. Res. Int. 2018, 6916797. doi:10.1155/2018/6916797

Xi, J., Xiang, S., and Zhang, H. (2020). Clinical Observation of Arbidol Combined with Diammonium Glycyrrhizinate in the Treatment of COVID-19. Chin. J. Hosp. Pharm. 40, 1287-1290.

Xie, X. W. (2017). Liquiritigenin Attenuates Cardiac Injury Induced by High Fructose-Feeding through Fibrosis and Inflammation Suppression. Biomed. Pharmacother. 86, 694-704. doi:10.1016/j.biopha.2016.12.066

Xie, Y. C., Dong, X. W., Wu, X. M., Yan, X. F., and Xie, Q. M. (2009). Inhibitory Effects of Flavonoids Extracted from Licorice on Lipopolysaccharide-Induced Acute Pulmonary Inflammation in Mice. Int. Immunopharmacol 9, 194-200. doi:10.1016/j.intimp.2008.11.004

Xiong, Y., Liu, Y., Cao, L., Wang, D., Guo, M., Jiang, A., et al. (2020). Transcriptomic Characteristics of Bronchoalveolar Lavage Fluid and Peripheral Blood Mononuclear Cells in COVID-19 Patients. Emerg. Microbes Infect. 9, 761-770. doi:10.1080/22221751.2020.1747363

Xu, W., Li, H. J., and He, Z. F, (2016). Research Progress on the Application of Glycyrrhiza Uralensis Extract in Food. Food Ferment. Ind. 42 (10), 274-281.

Xu, X., Chen, P., Wang, J., Feng, J., Zhou, H., Li, X., et al. (2020). Evolution of the Novel Coronavirus from the Ongoing Wuhan Outbreak and Modeling of its Spike Protein for Risk of Human Transmission. Sci. China Life Sci. 63, 457-460. doi:10.1007/s11427-020-1637-5

Yang, R., Wang, L. Q., Yuan, B. C., and Liu, Y. (2015). The Pharmacological Activities of Licorice. Planta Med. 81, 1654-1669. doi:10.1055/s-00351557893

Yang, R., Yuan, B. C., Ma, Y. S., Zhou, S., and Liu, Y. (2017). The Antiinflammatory Activity of Licorice, a Widely Used Chinese Herb. Pharm. Biol. 55, 5-18. doi:10.1080/13880209.2016.1225775

Yao, K., Chen, H., Lee, M. H., Li, H., Ma, W., Peng, C., et al. (2014). Licochalcone A, a Natural Inhibitor of C-Jun N-Terminal Kinase 1. Cancer Prev. Res. (Phila) 7, 139-149. doi:10.1158/1940-6207.CAPR-13-0117

Yu, J. Y., Ha, J. Y., Kim, K. M., Jung, Y. S., Jung, J. C., and Oh, S. (2015). AntiInflammatory Activities of Licorice Extract and its Active Compounds, Glycyrrhizic Acid, Liquiritin and Liquiritigenin, in BV2 Cells and Mice Liver. Molecules 20, 13041-13054. doi:10.3390/molecules200713041

Yu, S., Zhu, Y., Xu, J., Yao, G., Zhang, P., Wang, M., et al. (2020). Glycyrrhizin Exerts Inhibitory Activity against the Spike Protein of SARS-CoV2. Phytomedicine 153364.

Yuping, C., Xinji, L., Kefeng, L., and Xiaoxi, X. (2004). Clinical Observation of Compound Glycyrrhizin Injection in the Treatment of SARS Chin. pharm 5, 38-39.

Zadeh, J. B., Kor, Z. M., and Masoud, K. G. (2013). Licorice (Glycyrrhiza Glabra Linn) as a Valuable Medicinal Plant. Inter. J. Adv. Biol Biomed Res 1, 1281-1288.

Zhang, H., Penninger, J. M., Li, Y., Zhong, N., and Slutsky, A. S. (2020). Angiotensin-converting Enzyme 2 (ACE2) as a SARS-CoV-2 Receptor: Molecular Mechanisms and Potential Therapeutic Target. Intensive Care Med. 46, 586-590. doi:10.1007/s00134-020-05985-9

Zhang, H., Song, Y., and Zhang, Z. (2012). Glycyrrhizin Administration Ameliorates Coxsackievirus B3-Induced Myocarditis in Mice. Am. J. Med. Sci. 344, 206-210. doi:10.1097/MAJ.0b013e31823e2867 
Zhang, Y., Zhang, L., Zhang, Y., Xu, J. J., Sun, L. L., and Li, S. Z. (2016). The Protective Role of Liquiritin in High Fructose-Induced Myocardial Fibrosis via Inhibiting NF-Kb and MAPK Signaling Pathway. Biomed. Pharmacother. 84, 1337-1349. doi:10.1016/j.biopha.2016.10.036

Zhang, Y. S., Cong, W. H., Zhang, J. J., Guo, F. F., and Li, H. M. (2020). Research Progress of Intervention of Chinese Herbal Medicine and its Active Components on Human Coronavirus. Zhongguo Zhong Yao Za Zhi 45, 1263-1271. doi:10.19540/j.cnki.cjcmm.20200219.501

Zhao, Y. K., Li, L., Liu, X., Cheng, S. P., Guo, Q. Q., Fan, D. P., et al. (2016). Explore Pharmacological Mechanism of Glycyrrhizin Based on Systems Pharmacology. Zhongguo Zhong Yao Za Zhi 41, 1916-1920. doi:10.4268/ cjcmm20161026

Zhou, P., Yang, X. L., Wang, X. G., Hu, B., Zhang, L., Zhang, W., et al. (2020a). A Pneumonia Outbreak Associated with a New Coronavirus of Probable Bat Origin. Nature 579, 270-273. doi:10.1038/s41586-0202012-7

Zhou, S., Li, W., and Ai, Z. (2020b). Investigating Mechanism of Qingfei Dayuan Granules for Treatment of COVID-19 Based on Network Pharmacology and Molecular Docking. Chin. Tradit. Herbal Drugs 51, 1804-1813.

Zhou, T., Deng, X., and Qiu, J. (2012). Antimicrobial Activity of Licochalcone E against Staphylococcus aureus and its Impact on the Production of Staphylococcal Alpha-Toxin. J. Microbiol. Biotechnol. 22, 800-805. doi:10.4014/jmb.1112.12020

Zhou, W., Zhao, F., and Li, B. (2020c). Clinical Value of Diammonium Glycyrrhizinate in Treatment of COVID-19. Bing Du Xue Bao 36, $160-164$.
ZhuJie, D., Yongqiang, W., Xin, L., Xiaofeng, Z., Nana, L., Zurui, Z., et al. (2020). An Artificial Intelligence System Reveals Liquiritin Inhibits SARS-CoV2 by Mimicking Type I Interferon. BioRxiv.

Conflict of Interest: Z-cX was employed by the Gansu Qilian Mountain Pharmaceutical Limited Liability Company.

Authors X-fC and QS were employed by the company Sichuan Guangda Pharmaceutical Co. Ltd.

The remaining authors declare that the research was conducted in the absence of any commercial or financial relationships that could be construed as a potential conflict of interest.

Publisher's Note: All claims expressed in this article are solely those of the authors and do not necessarily represent those of their affiliated organizations, or those of the publisher, the editors and the reviewers. Any product that may be evaluated in this article, or claim that may be made by its manufacturer, is not guaranteed or endorsed by the publisher.

Copyright (c) 2021 Zhang, Huang, Qiu, Wu, Xin, Cai, Shang, Lin, Zhang, Han. This is an open-access article distributed under the terms of the Creative Commons Attribution License (CC BY). The use, distribution or reproduction in other forums is permitted, provided the original author(s) and the copyright owner(s) are credited and that the original publication in this journal is cited, in accordance with accepted academic practice. No use, distribution or reproduction is permitted which does not comply with these terms. 


\section{GLOSSARY}

ACE2 angiotensin-converting enzyme 2

AEC alveolar epithelial cell

ARDS acute respiratory distress syndrome

BALF broncho alveolar lavage fluid

COPD chronic obstructive pulmonary diseases

CRP C-reactive protein

CRS cytokine release syndrome

CVA 16 coxsackie virus A16

CYP450 cytochrome P450

DENV dengue virus

DHV duck hepatitis virus

EBOV ebola virus

EBV epstein-barr virus

ECM extracellular matrix

EMT epithelial-mesenchymal transition

EV 71 enterovirus 71

Fb Fibroblast

LA liquiritinapioside
LF licorice flavonoids

LPS lipopolysaccharides

MAPK mitogen-activated protein kinase

MARV marburg virus

MERS middle east respiratory syndrome

MIC minimum inhibitory concentration

MRSA methicillin-resistant Staphylococcus aureus

Nrf2 nuclear factor-E2 related factor2

HAV hepatitis A virus

HBV hepatitis B virus

HCV hepatitis $C$ virus

HIV human immunodeficiency virus

HRSV human respiratory syncytial virus

HSV-1 herpes simplex virus

PF pulmonary fibrosis

RBD receptor binding domain

ROS reactive oxygen species

SARS severe acute respiratory syndrome

VSV vesicular stomatitis virus

VZV varicella zoster virus 